\title{
EQUIDAD DE GÉNERO Y TRANSFORMACIÓN: PARTIIIPACIÓN Y LIDERAZGO LABORAL DE LA MUJER EN COLOMBIA
}

\section{Liliana Valencia Ramos}

\author{
Universidad de La Sabana \\ liliana.valencia1@unisabana.edu.co
}

Recibido: 22/03/2021

Aceptado: $19 / 04 / 2021$

\begin{abstract}
Resumen
En las últimas décadas, el Estado colombiano ha trabajado arduamente en la implementación de diversos mecanismos enfocados en derribar las barreras existentes para el género femenino, principalmente en lo relacionado con el reconocimiento de la mujer trabajadora, el acceso al mercado laboral y la retribución equitativa y justa, procurando acabar con diversos estereotipos que impiden que las mujeres se desarrollen en igualdad de condiciones frente al género masculino. Bajo la perspectiva de la normatividad internacional, se ha buscado mitigar aquellos actos discriminatorios que sufre la mujer, estableciendo algunos parámetros que sirven de guía a los diferentes Estados, con la finalidad principal de disminuir las brechas laborales existentes entre hombres y mujeres. A través de la adopción de medidas internas desarrolladas mediante modificaciones normativas, en Colombia se ha pretendido asegurar la participación plena y efectiva de la población femenina enfocada en el cumplimiento del objetivo de desarrollo sostenible de igualdad de género, procurando la apertura a la igualdad de oportunidades de liderazgo en los niveles laborales y sociales, promoviendo la equidad responsable en las relaciones de trabajo, permitiéndoles a las mujeres, en muchos casos, asumir el liderazgo de equipos de trabajo impulsando exitosas estrategias empresariales y alcanzando en la ocupación de altos cargos un gran impacto empresarial local y global.

Sea esta una oportunidad para abordar algunas de las causas estructurales de la desigualdad basada en el análisis planteado en este escrito, que muestra la necesidad imperiosa de una transformación estructural en la manera como se vincula la mujer en el mercado laboral al persistir las brechas diferenciales entre hombres y mujeres de décadas atrás, e invita a promover un mecanismo alternativo de cambio sustantivo en los niveles normativo y de ejecución para la transformación social y la inclusión de género.
\end{abstract}

Palabras clave: liderazgo, participación, enfoque de género, equidad, ley, política pública, discriminación de género, protección de la mujer trabajadora, paridad, igualdad, inclusión, empoderamiento. 


\title{
Gender Equity and Transformation: Participation and Labor Leadership of Women in Colombia
}

\begin{abstract}
In recent decades, the Colombian State has worked hard to implement various mechanisms focused on breaking down existing barriers for the female gender mainly in relation to the recognition of working women, access to the labor market and equitable and fair remuneration seeking to end various stereotypes that prevent women from developing on equal terms with men. From the perspective of international regulations, the aim has been to mitigate those discriminatory acts suffered by women by establishing some parameters that serve as a guide for the different States, with the main purpose of reducing the existing labor gaps between men and women. Through the adoption of internal measures developed through regulatory modifications, Colombia has sought to ensure the full and effective participation of the female population focused on the fulfillment of the sustainable development objective of gender equality seeking the opening of equal opportunities for leadership at labor and social levels, promoting responsible equity in work relations, allowing women in many cases to assume the leadership of work teams, driving successful business strategies and achieving great local and global business impact in the occupation of high positions.

This is an opportunity to address some of the structural causes of inequality based on the analysis presented in this paper, which shows the urgent need for a structural transformation in the way women are linked to the labor market given the persistence of the differential gaps between men and women from decades ago, and invites the promotion of an alternative mechanism for substantive change at the regulatory and implementation levels for social transformation and gender inclusion.
\end{abstract}

Key words: leadership, participation, gender approach, equity, law, public policy, gender discrimination, protection of working women, parity, equality, inclusion, empowerment.

\section{Introducción}

En la actualidad, en Colombia y en la mayoría de los países latinoamericanos, resulta evidente la necesidad de promover la participación, el liderazgo y el empoderamiento laboral de la mujer, promoviendo mecanismos que permitan disminuir las diferencias entre la empleabilidad y la calidad del empleo de hombres y mujeres y garantizando un enfoque de género con la finalidad de mitigar la inequidad de la mujer en este país. La existencia de trabajos especialmente reservados y caracterizados por el género que los ocupa supone un criterio de diferenciación que limita la entrada equitativa al mercado laboral de hombres y mujeres, vulnerando como consecuencia derechos considerados fundamentales para el ser humano.

La lucha por alcanzar la paridad en materia de derechos continúa siendo 
una problemática general actual; si bien muchos Estados han logrado reducir de manera significativa la brecha de desigualdad dirigida a la mujer brindándole oportunidades para crecer y realizarse en su ser y esencia, aún existen patrones sociales de conducta que violentan sus derechos, particularmente, y de manera significativa, sus derechos laborales.

En el presente escrito se pretende presentar un análisis en materia de empleabilidad de género en Colombia y, para esto, se presentan tres apartados desarrollados de la siguiente forma: el primero procura definir los conceptos de "enfoque de género", "liderazgo" y "participación de la mujer", y posteriormente se establecen las normas y otros documentos que contienen una política pública de empleo desde un enfoque de género en Colombia. En el segundo, se presentan los elementos diferenciales con enfoque de género aplicable en Colombia, la descripción de "equidad de género" e "igualdad de género" y la situación de los derechos de la mujer en Colombia. Finalmente, se identifican los sectores económicos que implementan en sus administraciones el enfoque de género como política de empleo, haciendo una breve presentación de las políticas públicas de empleo en los sectores económicos nacionales y la implementación en estos sectores del enfoque diferencial de género.

A nivel metodológico, esta investigación se realiza desde un enfoque cualitativo, como investigación de nivel descriptivo, procurando señalar las características y propiedades del enfoque de género en el diseño y ejecución de las políticas públicas de empleo en Colombia.

\section{Actualidad en materia de empleo con enfoque diferencial de género}

A lo largo de la historia de Colombia y de la gran mayoría de los países latinoamericanos, el empleo ha sido uno de los temas más importantes que ha acaparado el interés de los diferentes Gobiernos, y que en actualidad ha cobrado mayor relevancia por las implicaciones que ha tenido la pandemia que azota al mundo desde comienzos del año 2020, provocada por el COVID-19, y que ha conllevado una crisis sanitaria y económica en la mayoría de países, evidenciando las falencias de los modelos económicos actuales y las grandes deficiencias de los Estados en la destinación de recursos públicos para servicios básicos como la salud, poniendo de manifiesto la fragilidad de este sistema y la precarización de gran parte del sistema económico.

Como resultado de esta nueva realidad obligada, nos encontramos ante la responsabilidad de todos los habitantes del mundo de reconstruir nuestro es- 
tilo de vida desde una óptica distinta, la cual nos impida volver a la anterior normalidad destacada por la emergencia climática y la precarización de las condiciones de vida, discriminatoria evidentemente frágil de nuestros sistemas económicos, sociales y ambientales.

Sin embargo, al producirse una crisis como la actual, en la que nos hemos visto obligados a confinarnos y alejarnos del contacto social mientras avanza un plan adecuado de vacunación, nos vemos enfrentados a los efectos económicos y sociales de esta pandemia, que ha repercutido de manera directa en los índices de empleo de la mayoría de los países del mundo y que nos ha obligado a repensar las normas internas, dando un alcance especialísimo a las normas internacionales del trabajo para proporcionan una base sólida que nos permita actuar a nivel político, en razón de la necesidad humanitaria y de la función primordial que desempeña el trabajo decente para procurar una recuperación equitativa y sostenida.

Durante las últimas décadas, Colombia logró importantes avances en relación con la promoción de la igualdad de género y el empoderamiento de las mujeres en los diferentes sectores económicos y políticos, aunque existían aún brechas relevantes por reducir. Había una importante muestra de señales de crecimiento económico que vislumbraban una buena oportunidad para el progreso social y para el desarrollo humano. Si bien la participación de las mujeres en el mercado laboral venía incrementándose paulatinamente, las cifras seguían siendo muy por debajo de la paridad que hiciera justicia a la proporción de mujeres dentro de la sociedad.

Pero a raíz de la pandemia del COVID-19, la situación se hizo más complicada todavía, pues la existencia de brechas de género, en particular en la esfera económica, se ha hecho más evidente. El acceso de las mujeres al empleo formal y su participación en el mercado laboral se vio afectado, incrementando aún más la diferencia de género que había mejorado años atrás.

Este resultado, que no ha sido exclusivo de Colombia, es un claro reflejo de la situación que atraviesan muchos países latinoamericanos, donde resulta más que necesario para combatir los efectos que ha traído consigo el COVID-19. Se necesita no solo la implementación de una política clara encaminada a generar una mayor vinculación de personal al mercado laboral, sino también un mayor acceso a empleos de calidad que realmente dignifiquen la calidad de personas en cada Estado y un mayor esfuerzo para superar de manera efectiva las altas tasas de informalidad presentes en las economías latinoamericanas.

Para Colombia, en la actualidad, la situación en materia de empleo resulta 
ser una de sus mayores prioridades en el en el ámbito estatal, en un marco bajo el cual se han construido y ejecutado una serie de políticas públicas que determinan la intención del Gobierno de superar la crisis que ha traído consigo la pandemia, y simultáneamente disminuir las cifras de desempleo actuales, procurando garantizar empleos dignos en el marco del desarrollo de una serie de iniciativas e instrumentos legales que concretan esa política pública disponiendo de recursos e instituciones diseñadas para esta labor.

En este sentido, resulta necesario mencionar qué se ha definido en Colombia como "política pública" y en qué consiste la estrategia de esta para garantizar el acceso a los derechos individuales, principalmente en materia de empleo, desde un enfoque de género que incluya la participación, la igualdad y equidad de género y el liderazgo de las mujeres en los diferentes escenarios.

\title{
3. Desarrollo del concepto de "igualdad de género" en el ámbito internacional
}

La discriminación puede entenderse como la acción dirigida a excluir o brindar un trato diferencial o desigual a un individuo o a una comunidad, con base en sus creencias, pensamientos, actitudes, condición física, sexual, entre otras. De esta forma, "discriminación" hace referencia a:

\begin{abstract}
Cualquier distinción, exclusión o preferencia basada en motivos de raza, color, sexo, religión, opinión política, ascendencia nacional u origen social que tenga por efecto anular o alterar la igualdad de oportunidades o de trato en el empleo y la ocupación. (Organización Internacional del Trabajo [OIT], 1958)
\end{abstract}

De acuerdo con lo manifestado por la OIT (2014) en Igualdad de género y no discriminación en la gestión del empleo. Guía para la Acción, existen dos formas de discriminación laboral por razones de género: la primera, denominada discriminación directa, que se refiere a aquella que se da de manera expresa, excluyendo explícitamente a las personas que no sean parte de dicha categoría. La segunda, denominada discriminación indirecta, no se manifiesta de manera explícita, pero puede darse al establecer condiciones que imposibilitan el acceso de la mujer, en cuanto a que esta cumple tradicionalmente un rol específico en la sociedad (madre, esposa, hija, cuidadora, entre otros) que la sitúa en una posición de desventaja con respecto a los hombres, quienes, a su vez, tradicionalmente no ocupan estos roles. Muestra de esto es cuando la oferta laboral exige disponibilidad horaria completa o cuando, aun sin manifestarlo expresamente, se presupone que la mujer, por el hecho de ser mujer, no podría desempeñar una u otra labor. 
Desde la década de 1990, muchos países han decidido ser parte de convenios internacionales, cuya finalidad es promover la igualdad de género y erradicar la desigualdad hacia la mujer. Prueba de esto es que la mayoría de los países del mundo han ratificado el Convenio 111 de la OIT sobre la discriminación en el empleo y la ocupación. Asimismo, en el año 2007, Colombia y Argentina ratificaron el Protocolo Facultativo de la Convención sobre la eliminación de todas las formas de discriminación contra la mujer, adoptado por la Asamblea General de las Naciones Unidas en el año 1999 (CEPAL, 2019).

La lucha por alcanzar la paridad en materia de derechos sigue siendo una problemática actual. Si bien muchos Estados han logrado reducir de manera significativa la brecha de desigualdad dirigida a la mujer brindándole oportunidades para crecer y realizarse en su ser y esencia, aún existen patrones sociales de conducta que vulneran sus derechos, particularmente los laborales de manera significativa. Países como Islandia, que de acuerdo con el índice del Foro Económico Mundial ha ocupado en los últimos años el primer lugar en igualdad de género, como lo mencionó la OIT (2019), han logrado reducir la brecha de género en el ambiente laboral gracias a la creación de medidas legislativas que obligan a las empresas e instituciones con 25 o más empleados a obtener un "certificado de igualdad salarial que demuestre la aplicación del principio igual salario a igual trabajo.

La Convención sobre la eliminación de todas las formas de discriminación contra la mujer (Asamblea General de las Naciones Unidas, 1979), ratificada por Colombia a través de la Ley 51 de 1981, establece específicamente respecto al ámbito laboral el derecho a igual remuneración, a la igualdad de trato con respecto a un trabajo de igual valor, a la protección de la mujer durante el embarazo y el derecho a las mismas oportunidades de empleo en relación con el reconocimiento de las mismas capacidades que tienen frente al hombre. Garantías estas que, a pesar de generar obligaciones de carácter internacional para los Estados parte, todavía resultan ser vulneradas en la cotidianidad empresarial e institucional.

Asimismo, la Convención Interamericana para Prevenir, Sancionar y Erradicar la Violencia contra la Mujer (Organización de los Estados Americanos, 1994), ratificada por Colombia a través de la Ley 248 de 1995, además de reconocer el derecho a ser libre de toda forma de discriminación, determina que el acoso sexual en el lugar de trabajo -que tiene como principales víctimas a las mujeres- debe entenderse como violencia hacia la mujer, instando dicha normatividad a los Estados parte para que, dentro de muchas otras obligaciones, 
actúen con la debida diligencia para prevenir, investigar y sancionar todo tipo de violencia contra la mujer a través de normas de cualquier naturaleza.

En el mismo sentido, con miras hacia la protección de los derechos laborales de las mujeres, el Convenio 100 de la OIT sobre igualdad de remuneración (1951), ratificado por Colombia a través de la Ley 54 de 1962 (al cual nos remitiremos en profundidad más adelante), establece "el derecho fundamental a la igualdad de remuneración por un trabajo de igual valor" (OIT, 2014, p. 62). Esta disposición se aplica a todos los trabajadores, indistintamente de su género, nacionalidad o labor realizada.

\subsection{Acercamiento al concepto de "políticas públicas"}

El término "políticas públicas" hace referencia principalmente a la concreción de los fines del Estado en acciones que determinen el bienestar general de sus asociados. En este sentido, Ruiz y Cádenas (2005) han definido este concepto como un comportamiento propositivo, intencional, planeado, no simplemente reactivo, casual. Se pone en movimiento con la decisión de alcanzar ciertos objetivos a través de ciertos medios: es una acción con sentido. Es un proceso, un curso de acción que involucra a todo un conjunto complejo de decisiones y operadores, por lo tanto, la política pública implica un ejercicio de acción por parte del Estado y genera la instauración de un diálogo permanente con los asociados, que, en últimas, es lo que va a determinar en gran medida cómo la administración realizará su manifestación pública.

De esta manera, la política también implica una actividad de comunicación pública, por tanto, el papel que juega la política pública al interior de una sociedad supone legitimar al Estado no solo por su carácter instrumental en la provisión de servicios básicos o la administración de bienes públicos, sino que determina una apuesta socio-política para resolver problemas públicos concretos y necesidades individuales y colectivas que son definidas por la misma sociedad (Maurizio, 2010). Además, las políticas públicas de un país se encuentran determinadas en gran medida por la manera en que este concibe al Estado y por los valores sobre los cuales se encuentra fundado.

De esta forma, en Colombia, la política pública resulta ser un instrumento en el cual participa la comunidad y el Gobierno, encaminada a dar soluciones a situaciones específicas y frente a las cuales todas las personas deben regirse. Es un elemento que pone en marcha el ejercicio de la democracia que está en constante construcción y lleva implícito un sistema de evaluación, por consiguiente, 
no se trata de un ejercicio exclusivamente gubernamental, sino de construcción colectiva y conjunta, en el que la sociedad establece su postura frente a las necesidades que tiene y el Gobierno propone salidas acordes a la manera en cómo la sociedad interpreta cada situación, procurando establecer la ruta necesaria para contar con políticas públicas que respondan a las necesidades de los ciudadanos colombianos.

\subsection{Políticas públicas de empleabilidad en Colombia}

Bajo el concepto de "políticas públicas de empleo", en Colombia, el diseño de estas se encuentra bajo la gestión del Ministerio del Trabajo, entidad del orden nacional que ha dirigido su actividad hacia cuatro pilares fundamentales que cimientan las acciones que se emprenden en esta materia y que ha presentado modificaciones debido a la crisis actual por la pandemia del COVID-19: a) la disminución de la tasa de desempleo; b) el incremento de la tasa general de participación; c) el incremento en la calidad del empleo mediante la aplicación de políticas activas y pasivas; y d) el aumento de la productividad.

Frente a estas tareas, el Ministerio realiza su labor institucional en tres niveles de gestión. En primer lugar, está la estructura de trabajo, compuesta por las instituciones que tienen competencias para la generación de empleo y para el desarrollo de la política de mercado de trabajo. Es decir, se encarga de la administración y gestión política. El segundo nivel compromete a la gestión de las políticas que inciden directamente en la generación de empleo y en la participación laboral del país y las políticas pasivas, que se limitan a mantener o distribuir el ingreso del mercado de trabajo. El tercer nivel corresponde a la coordinación, que implica la interrelación con los sistemas que permiten el aseguramiento de los trabajadores, como el de seguridad social y el de promoción social, además de la estrategia de gestión del recurso humano (Observatorio del Servicio Público de Empleo, 2020).

Bajo esta estructuración de labor institucional, el Ministerio del Trabajo materializa a través del documento de planeación nacional -el cual tiene carácter de ley de la república- denominado Plan Nacional de Desarrollo (PND), construido cada cuatro años y que sirve de ruta para cada Gobierno, coincidiendo con el período presidencial nacional.

El PND suele complementarse con documentos del Consejo Nacional de Política Económica y Social (CONPES), que incluyen recursos para la implementación de las políticas que contienen, y entre los dos se trabaja en la búsqueda 
de los objetivos trazados por las políticas macroeconómicas, armonizando las acciones para que los objetivos en materia de empleo no vayan en contravía de las apuestas económicas y sociales que ha realizado el país.

El último cuatrienio ha sido el escenario para la implementación de una política pública en materia de empleo que tiene un marco macroeconómico favorable al empleo decente, pleno, productivo, libremente elegido y al desarrollo de las empresas sostenibles, las cuales propenden al crecimiento económico y la inclusión social.

La política del PND contiene los propósitos y objetivos nacionales a largo plazo, las metas y prioridades de la acción estatal a mediano plazo y las estrategias y orientaciones generales de la política económica, social y ambiental que serán adoptadas de inmediato. Todo esto, modificado a través de algunos decretos sancionados durante la emergencia sanitaria declarada por la pandemia del COVID-19.

En la actualidad, en este documento se incluyen los lineamientos relativos a:

Política Nacional de Trabajo Decente y Formalización; control a la tercerización ilegal; fortalecimiento del diálogo social; mejoramiento continuo del Sistema de Inspección, Vigilancia y Control Laboral y cobro de multas; metas claras para la reducción de la tasa de desempleo; protección eficaz al trabajador cesante; protección eficaz a la vejez; y fortalecimiento del régimen y sistema de seguridad y salud en el trabajo. (Departamento Nacional de Planeación, 2014)

La Política de Trabajo Decente está orientada a promover la generación de empleo, la formalización laboral y la protección de los trabajadores de los sectores público y privado. Igualmente, a la aplicación de los estándares laborales internacionales que se desprenden de los compromisos asumidos por Colombia en escenarios bilaterales, multilaterales e internacionales, muy especialmente los que tienen origen en la OIT.

\subsection{Desarrollo normativo y alcance general}

Colombia, atendiendo a las necesidades de generar políticas claras que garanticen un enfoque diferencial de género, ha ratificado todos los tratados internacionales vigentes sobre derechos humanos y derechos de las mujeres, y ha demostrando un avance significativo en el desarrollo de un ordenamiento interno que garantice la promoción de la igualdad de género y el respeto por los derechos humanos de las mujeres. 
Algunas claras muestras de este trabajo se reflejan en la Ley 1257 "Por la cual se dictan normas de sensibilización, prevención y sanción de formas de violencia y discriminación contra las mujeres" del año 2008; la Ley de Víctimas y Restitución de Tierras, aprobada en 2011 con disposiciones importantes sobre la igualdad de género; los Lineamientos de la Política Pública para la Equidad de Género para las Mujeres y el Plan Integral para garantizar a las mujeres una vida libre de violencias, aprobados en el año 2012; así como la Ley 1719 por la cual se adoptan medidas para garantizar el acceso a la justicia de las víctimas de violencia sexual, en especial la violencia sexual con ocasión del conflicto armado, del año 2014, entre otras.

\section{Convenio 100 de la Organización Internacional del Trabajo}

Este convenio aborda la igualdad de remuneración entre la mano de obra masculina y la mano de obra femenina por un trabajo de igual valor, cuya entrada en vigor fue el 23 mayo de 1953. A pesar de los años transcurridos desde su promulgación, todo su contenido sigue vigente y pertinente en el escenario colombiano (y en el escenario latinoamericano en general), razón por la cual constituye un elemento esencial a la hora de establecer posibles violaciones a los derechos de las mujeres y para enmarcar iniciativas de planes y proyectos encaminados al trabajo y empleo de las mujeres en condiciones igualitarias.

Este convenio sugiere la promoción para garantizar la aplicación a todos los trabajadores del principio de igualdad de remuneración entre la mano de obra masculina y la mano de obra femenina por un trabajo de igual valor, promoviendo la evaluación objetiva del empleo.

Este instrumento de carácter internacional establece que sus miembros deberán adoptar métodos que les permitan establecer las tasas de remuneración que respondan a métodos necesarios para construir estándares de pago que atiendan criterios de igualdad entre el género femenino y el masculino, para lo cual determina que, adicionalmente, se establece la necesidad de utilizar la legislación nacional como medio para este fin o directamente de manera contractual a partir de los modelos de contratos colectivo o la utilización de estos mecanismos de manera conjunta; permitiendo de esta forma una flexibilidad que garantice a los Estados miembros de la OIT valerse del instrumento que mejor se acomode a sus políticas y a su entorno económico y social, procurando así el mantenimiento de un equilibrio salarial.

Por otra parte, este convenio representa una base fundamental en el proceso de lucha por la igualdad entre hombres y mujeres en materia laboral y represen- 
ta un camino al respaldo internacional para sus iniciativas de igualdad salarial dentro de su territorio. Sin embargo, su aplicación no se ha dado de una manera equitativa y justa, pues en la actualidad se presentan diferencias salariales entre hombres y mujeres, situación que responde más a un patrón cultural por la falta de denuncia de estas situaciones. De igual manera, hay una ausencia de mecanismos judiciales en nuestro ordenamiento jurídico que realmente procuren garantizar su cumplimiento, especialmente en el sector privado.

\section{Convenio 111 de la Organización Internacional del Trabajo}

Convenio sobre la discriminación relativo a la discriminación en materia de empleo y ocupación implementado el 15 junio 1960. Define el término "discriminación" desde dos perspectivas, indicando que este concepto se refiere, por una parte, a cualquier distinción, exclusión o preferencia basada en motivos de raza, color, sexo, religión, opinión política, ascendencia nacional u origen social que tenga por efecto anular o alterar la igualdad de oportunidades o de trato en el empleo y la ocupación; y, por otra parte, a cualquier otra distinción, exclusión o preferencia que tenga por efecto anular o alterar la igualdad de oportunidades o de trato en el empleo u ocupación que podrá ser especificada por el miembro interesado previa consulta con las organizaciones representativas de empleadores y de trabajadores, cuando dichas organizaciones existan, y con otros organismos apropiados.

Además de esta definición, el Convenio compromete a sus miembros a formular y a llevar a cabo una política nacional que promueva, por métodos adecuados a las condiciones y a la práctica nacionales, la igualdad de oportunidades y de trato en materia de empleo y ocupación, con objeto de eliminar cualquier discriminación a este respecto. En este sentido, el artículo 2 de este instrumento determina

Todo Estado Miembro para el cual este Convenio se halle en vigor se obliga a formular y llevar a cabo una política nacional que promueva, por métodos adecuados a las condiciones y a la práctica nacionales, la igualdad de oportunidades y de trato en materia de empleo y ocupación, con objeto de eliminar cualquier discriminación a este respecto.

Así las cosas, pese a que este instrumento no define cuáles son los "métodos adecuados", pone en cabeza de los Estados la definición, según su realidad particular, de la forma en cómo darle cumplimiento. Este documento no se refiere concretamente a la mujer como sujeto de especial protección, pero resulta importante toda vez que se pronuncia contra cualquier forma de discriminación. 
Con este convenio, la comunidad internacional avanza en la protección del derecho a la igualdad desde el ámbito laboral, estableciendo a la discriminación como una situación anómala frente a la que se deben unir fuerzas para su erradicación, y esboza lo que posteriormente se desarrollará en varios instrumentos de carácter internacional respecto a la protección de los derechos de la mujer, pero abordándolos desde un enfoque de género en el que se marca una diferencia entre hombre y mujer y se reconocen las necesidades particulares de cada uno.

\title{
Constitución Política de Colombia
}

La Corte Constitucional de Colombia ha logrado identificar vulneraciones al derecho a la igualdad y, para el tema que compete en particular, discriminaciones basadas en género. En el ordenamiento jurídico nacional, el artículo 13 de la Constitución Política de Colombia, que consigna el Derecho a la Igualdad, establece que:

\begin{abstract}
Todas las personas nacen libres e iguales ante la ley, recibirán la misma protección y trato de las autoridades y gozarán de los mismos derechos, libertades y oportunidades sin ninguna discriminación por razones de sexo, raza, origen nacional o familiar, lengua, religión, opinión política o filosófica.
\end{abstract}

Este artículo representa el principal referente para el posterior desarrollo de diferentes instrumentos legales para la protección de los derechos de la mujer y la concreción de políticas públicas desde enfoques diferenciales, reconociendo las diferencias que coexisten en una sociedad caracterizada por su diversidad.

Por su parte, la primera referencia constitucional de protección específica a la mujer se encuentra en el artículo 40, en el cual se establece la obligación para el Estado de garantizar el acceso de la mujer a los niveles decisorios de la Administración Pública, evidenciando con ello un tratamiento especial en el que se confirma un derecho que, en principio, es de todos los ciudadanos, pero que por la circunstancia cultural debe ser reforzado para las mujeres.

La Constitución Política de Colombia también determina la facultad del Congreso Nacional de promover medidas de acción positiva en relación con las mujeres que garanticen la igualdad de oportunidades y el pleno goce y ejercicio de los derechos reconocidos por la Constitución y los Tratados Internacionales (artículo 75, inciso 23). Por su parte, el artículo 43 consagra que: "La mujer y el hombre tienen iguales derechos y oportunidades. La mujer no podrá ser sometida a ninguna clase de discriminación”.

Con la constitución de 1991 y en el marco del Estado social de derecho, 
Colombia establece una nueva forma de asumir el Estado y la protección de los derechos de sus ciudadanos, en la que la igualdad entre hombres y mujeres representa la concreción de una serie de medidas legales que desde décadas anteriores venían introduciéndose al ordenamiento jurídico nacional, con la finalidad de garantizar el acceso de la mujer a espacios que históricamente se le habían cerrado.

En términos generales, la Constitución Política y su nuevo enfoque de derechos representa un respaldo fundamental en el desarrollo posterior de la legislación y de la política pública en torno a la equidad de género y al empoderamiento femenino en Colombia, toda vez que, al tener el rango de constitucional, estas normas son susceptibles de ser reclamadas por vía de tutela, la cual representa un gran avance en términos de defensa de derechos por su efectiva e inmediata acción.

\section{Código Sustantivo del Trabajo}

Desde la legislación laboral nacional se concretó este derecho a la igualdad en el marco de las relaciones obrero-patronales, estableciendo en el artículo 10 del Código Sustantivo del Trabajo la igualdad de los trabajadores y las trabajadoras:

\footnotetext{
Todos los trabajadores y trabajadoras son iguales ante la ley, tienen la misma protección y garantías, en consecuencia, queda abolido cualquier tipo de distinción por razón del carácter intelectual o material de la labor, su forma o retribución, el género o sexo salvo las excepciones establecidas por la ley.
}

A partir de este concepto, se empezó a vislumbrar la línea de protección de las mujeres en términos laborales, lo que años más tarde le daría paso a la política pública, que hoy se está implementando en el territorio colombiano.

El Código Sustantivo del Trabajo representa la norma más importante en materia laboral en Colombia, de ahí la importancia de que en esta norma se haga referencia al tema específico de la igualdad de la mujer frente a su calidad de trabajadora, situación que le permite gozar de las mismas protecciones que un trabajador (hombre); por tanto, pone de manifiesto al empleador la obligación de un tratamiento en igualdad de condiciones a ambos sexos.

Esta norma también contempla una protección especial a la trabajadora embarazada sobre la prohibición de despedirla:

Ninguna trabajadora puede ser despedida por motivo de embarazo o lactancia. Se presume que el despido se ha efectuado por motivo de embarazo o lactancia, 
cuando ha tenido lugar dentro del período de embarazo o dentro de los tres meses posteriores al parto, y sin autorización de las autoridades de que trata el artículo siguiente [...].

Igualmente, el artículo 240 del Código Sustantivo del Trabajo expresa:

Permiso para despedir. 1. Para poder despedir a una trabajadora durante el período de embarazo o los tres meses posteriores al parto, el patrono necesita la autorización del inspector de trabajo, o del alcalde municipal en los lugares donde no existiere aquel funcionario. 2. El permiso de que trata este artículo sólo puede concederse con fundamento en alguna de las causas que tiene el patrono para dar por terminado el contrato de trabajo y que se enumera en los artículos 62 y 63 . Antes de resolver el funcionario debe oír a la trabajadora y practicar todas las pruebas conducentes solicitadas por las partes. 3. Cuando sea un alcalde municipal quien conozca de la solicitud de permiso, su providencia tiene carácter provisional y debe ser revisada por el inspector del trabajo residente en el lugar más cercano.

Este artículo contenido en la norma en cuestión representa la materialización de la concepción de la aplicación de un trato diferenciado, situación conocida como "acciones de diferenciación afirmativa", concepto definido por la Corte Interamericana de Derechos Humanos, que ha manifestado:

\begin{abstract}
Al examinar las implicaciones del trato diferenciado que algunas normas pueden dar a sus destinatarios, es importante hacer referencia a lo señalado por este Tribunal en el sentido que no toda distinción de trato puede considerarse ofensiva, por sí misma, de la dignidad humana. Pueden establecerse distinciones, basadas en desigualdades de hecho, que constituyen un instrumento para la protección de quienes deban ser protegidos.
\end{abstract}

Es así como la norma utiliza esta figura materializando una situación en la que se privilegia a la mujer, teniendo en cuenta las necesidades que son propias de su género, presentando con ello una línea de trabajo en la que se le otorga a la mujer consideraciones especiales en aras de garantizar su ejercicio de derechos y, como el caso de la norma analizada, reivindicar la labor que realizan dentro de la sociedad, adicional a su condición de trabajadora.

\title{
Ley 51 de 1981
}

Por medio de esta ley se ratifica la Convención Internacional sobre la Eliminación de todas las Formas de Discriminación contra la Mujer - CEDAW para 
Colombia. Fue desarrollada posteriormente mediante el Decreto 1398 del 3 de julio de 1990. Con esta normatividad, la expresión discriminación contra la mujer denota toda distinción, exclusión o restricción basada en el sexo que tenga por objeto o por resultado menoscabar o anular el reconocimiento, goce o ejercicio de la mujer, independientemente de su estado civil, de los derechos humanos y de las libertades fundamentales en las esferas política, económica, social, cultural y civil o en cualquier otra.

Esta ley reconoce que para lograr la plena igualdad entre el hombre y la mujer, es necesario modificar el papel de cada uno en la sociedad y en la familia, por lo que busca reivindicar los derechos del género femenino en una declaración sobre la eliminación de la discriminación contra la mujer, adoptando las medidas necesarias a fin de suprimir cualquier tipo de discriminación en todas sus formas y manifestaciones.

La norma es desarrollada por el Decreto 1398 de 1990, en el que se define la discriminación contra la mujer como toda distinción, exclusión o restricción basada en el sexo que tenga por objeto o por resultado menoscabar o anular el reconocimiento, goce o ejercicio de la mujer, independientemente de su estado civil, sobre la base de igualdad del hombre y la mujer, de los derechos humanos y las libertades fundamentales en las esferas política, económica, social, cultural y civil o en cualquier otra.

\section{Ley 248 de 1995}

Con esta ley se convierte en legislación nacional la Convención Belem do Pará (contra la violencia hacia las mujeres) y se afirma el deber de "fomentar y apoyar programas de educación gubernamentales y del sector privado destinados a concienciar al público sobre los problemas relacionados con la violencia contra la mujer, los recursos legales y la reparación que corresponda" (artículo 8). Esta convención fue diseñada para prevenir, sancionar y erradicar toda forma de violencia contra la mujer en el ámbito de la Organización de los Estados Americanos, convirtiéndose en un instrumento de protección de los derechos de la mujer. En esta línea, se destaca:

ARTÍCULO 8o. Los Estados Partes convienen en adoptar, en forma progresiva, medidas específicas, inclusive programas para:

a) Fomentar el conocimiento y la observancia del derecho de la mujer a una vida libre de violencia, y el derecho de la mujer a que se respeten y protejan sus derechos humanos;

b) Modificar los patrones socioculturales de conducta de hombres y mujeres, 
incluyendo el diseño de programas de educación formales y no formales apropiados a todo nivel del proceso educativo, para contrarrestar prejuicios y costumbres y todo otro tipo de prácticas que se basen en la premisa de la inferioridad o superioridad de cualquiera de los géneros o en los papeles estereotipados para el hombre y la mujer que legitimizan o exacerban la violencia contra la mujer;

c) Fomentar la educación y capacitación del personal en la administración de justicia, policial y demás funcionarios encargados de la aplicación de la ley, así como del personal a cuyo cargo esté la aplicación de las políticas de prevención, sanción y eliminación de la violencia contra la mujer;

d) Suministrar los servicios especializados apropiados para la atención necesaria a la mujer objeto de violencia, por medio de entidades de los sectores público y privado, inclusive refugios, servicios de orientación para toda la familia, cuando sea del caso, y cuidado y custodia de los menores afectados;

e) Fomentar y apoyar programas de educación gubernamentales y del sector privado destinados a concientizar al público sobre los problemas relacionados con la violencia contra la mujer, los recursos legales y la reparación que corresponda; f) Ofrecer a la mujer objeto de violencia acceso a programas eficaces de rehabilitación y capacitación que le permitan participar plenamente en la vida pública, privada y social;

g) Alentar a los medios de comunicación a elaborar directrices adecuadas de difusión que contribuyan a erradicar la violencia contra la mujer en todas sus formas y a realzar el respeto a la dignidad de la mujer;

h) Garantizar la investigación y recopilación de estadísticas y demás información pertinente sobre las causas, consecuencias y frecuencia de la violencia contra la mujer, con el fin de evaluar la eficacia de las medidas para prevenir, sancionar y eliminar la violencia contra la mujer y de formular y aplicar los cambios que sean necesarios, y

i) Promover la cooperación internacional para el intercambio de ideas y experiencias y la ejecución de programas encaminados a proteger a la mujer objeto de violencia.

La Convención de Belém do Pará (1995) reconoce por primera vez el derecho de las mujeres a vivir una vida libre de violencia, razón por la cual establece las medidas descritas anteriormente como fórmula para que los Estados les garanticen una existencia segura libre de cualquier manifestación de violencia.

Con esta ley, el Estado colombiano integra a la legislación nacional un compromiso regional frente a la protección de la mujer y la reivindicación de su papel en la sociedad. Esta Ley sigue la línea de los convenios de la OIT ratificados por Colombia, sin embargo, para la fecha de su expedición, todavía no representaba un antecedente para la concreción de una política pública con enfoque de género. 
Decreto 1182 de 1999

Este Decreto establece la transformación de la Dirección Nacional para la Equidad de las Mujeres en Consejería Presidencial para la Equidad de la Mujer, asumiendo como misión

diseñar, promover, coordinar e implementar una política para las mujeres adultas, jóvenes y niñas, que Mujeres y sus derechos contribuya al logro de relaciones de equidad y de igualdad de oportunidades entre mujeres y hombres, eleve la calidad de vida de las mujeres, el respeto de los derechos humanos, la participación ciudadana, e impulse el fortalecimiento de los procesos organizativos y de las organizaciones de mujeres

Así, busca estructurar la política nacional para las mujeres, transversalizar dicha política en la Administración Pública y fortalecer su institucionalización.

Con la creación de esta consejería, el tema de género se ubica en la escena nacional y se empiezan a desarrollar investigaciones e iniciativas desde lo gubernamental para reivindicar al género femenino en la sociedad, teniendo en cuenta que una de sus principales tareas consistía en impulsar la incorporación de la perspectiva de género en la formulación y gestión de las políticas, planes, programas y proyectos de desarrollo por parte de todas las entidades públicas, sectoriales y territoriales.

Con este decreto se abrió paso a una nueva forma de asumir la igualdad entre hombres y mujeres y se incorpora la necesidad de políticas públicas construidas desde un enfoque de género, convirtiéndose esta consejería en un ente rector en la materia; y el tema, en una realidad a concretar en los niveles nacional, departamental y local.

\section{Ley 581 de 2000}

Esta ley reglamenta la adecuada y efectiva participación de las mujeres en los niveles decisorios de las diferentes ramas y órganos del poder público. Se expidió en desarrollo de los artículos 13, 40 y 43 de la Constitución Política, que les garantizan derechos fundamentales a las mujeres. Es una ley estatutaria que busca crear mecanismos para que las autoridades, en cumplimiento de los mandatos constitucionales, les otorguen a las mujeres la adecuada y efectiva participación a la que tienen derecho en todos los niveles de las ramas y órganos del poder público.

La ley tiene como fundamento darle mayor representatividad a la mujer en la política, en un contexto en el que esta se ve discriminada por la cultura 
y los distintos códigos que las relegan de los roles de autoridad. Se pretende generar nuevas formas de liderazgo a través de la participación de la mujer en el ámbito político.

Sin embargo, teniendo en cuenta que la postura de Ley de cuotas implica también un ejercicio de desigualdad, la Corte Constitucional, en Sentencia C-371 de 2000, debió pronunciarse acerca de dicha postura, indicando que "si bien pueden generar una desigualdad, lo hacen como medio para conseguir el fin de una sociedad menos inequitativa y más acorde con el propósito consignado en el artículo 2० de la Carta, de perseguir un orden justo”; presentándose entonces como instrumento que destruye la igualdad como método para garantizar participación.

De los apartes más relevantes de esta norma se encuentra el artículo 4, en el que se define el porcentaje de participación femenina en los cargos de carácter estatal. La norma reza:

ARTÍCULO 4o. Participación efectiva de la mujer. La participación adecuada de la mujer en los niveles del poder público definidos en los artículos 2o. y 3 o. de la presente ley, se hará efectiva aplicando por parte de las autoridades nominadoras las siguientes reglas:

a) Mínimo el treinta por ciento (30\%) de los cargos de máximo nivel decisorio, de que trata el artículo 2o., serán desempeñados por mujeres;

b) Mínimo el treinta por ciento (30\%) de los cargos de otros niveles decisorios, de que trata el artículo 3o., serán desempeñados por mujeres.

PARÁGRAFO. El incumplimiento de lo ordenado en este artículo constituye causal de mala conducta, que será sancionada con suspensión hasta de treinta (30) días en el ejercicio del cargo, y con la destitución del mismo en caso de persistir en la conducta, de conformidad con el régimen disciplinario vigente.

En este sentido, cuando la norma indica que un mínimo del treinta por ciento (30\%) de los cargos del máximo nivel decisorio serán desempeñados por mujeres, se refiere a los cargos de mayor jerarquía en las entidades de las tres ramas y órganos del poder público, en los niveles nacional, departamental, regional, provincial, distrital y municipal. Asimismo, se aplica dicho porcentaje a los cargos de otro nivel decisorio, es decir, cargos de libre nombramiento y remoción, de la Rama Ejecutiva, del personal administrativo de la Rama Legislativa y de los demás Órganos del Poder Público en todos los niveles.

Para el cumplimiento de la ley, los nominadores deben tener en cuenta que la cuota aplica a cada categoría de cargos, es decir, un mínimo del treinta por ciento (30\%) de cada uno de los cargos del máximo nivel decisorio deben ser 
ocupados por mujeres. Pese a que mediante esta norma se garantiza un porcentaje de participación, alrededor de esta surgen posiciones encontradas, teniendo en cuenta que el 30\% no corresponde a una cifra equilibrada, permitiendo con ello que el género masculino siga asumiendo una hegemonía respaldada por la misma norma.

Las leyes de cuotas pertenecen a las denominadas "leyes de acción positiva" y se sustentan en el reconocimiento de la existencia de diversas formas de discriminación y en la voluntad para superarlas. Es un esfuerzo para hacer efectiva la igualdad, puesto que la conquista formal de un derecho no es suficiente para que este se aplique y, por consiguiente, son necesarias intervenciones que reparen la desigualdad. Esta ley ha sido duramente criticada debido a que el ejercicio de discriminación positiva implica para muchos sectores un reconocimiento tácito de imposibilidad o incapacidad por parte del género femenino, además del hecho de que en muchos casos la ley no ha servido como mínimo, sino como un techo, limitando en gran medida la participación de muchas mujeres en ejercicios políticos importantes.

\section{Ley 731 de 2002}

Esta norma tiene por objeto mejorar la calidad de vida de las mujeres rurales priorizando las de bajos recursos- y consagrar medidas específicas encaminadas a acelerar la equidad entre el hombre y la mujer rural, entendiendo por esta toda aquella que, sin distingo de ninguna naturaleza e independientemente del lugar donde viva, su actividad productiva está relacionada directamente con lo rural, incluso si dicha actividad no es reconocida por los sistemas de información y medición del Estado o no es remunerada.

Con esta norma se da una marcada presencia de medidas a favor de la mujer rural, entendiéndola como un universo diferente por su condición de mujer y por su forma de vida rural. Por esta razón, procura facilitar accesos a líneas de crédito especializadas, posibilidades de educación y además genera espacios para la participación de estas mujeres en el desarrollo político del país, logrando con ello una nueva visión más integral de la mujer, aunque en esta oportunidad se encuentre sesgada por el criterio de la ruralidad.

Resulta importante el hecho de que la misma ley defina las líneas de trabajo y las fuentes de financiación, lo que le da una vocación de ejecución un tanto más amplia que otras que se quedan en lo abstracto y a las que les cuesta desarrollar medidas de impacto para la comunidad.

Esta ley se fundamenta en el reconocimiento constitucional de la igualdad 
jurídica, real y efectiva de derechos y oportunidades de mujeres y hombres, en el respeto de la dignidad humana y en los principios consagrados en los acuerdos internacionales sobre esta materia. La igualdad de oportunidades para las mujeres, y especialmente para las niñas, es parte inalienable, imprescriptible e indivisible de los derechos humanos y libertades fundamentales.

Para el cumplimiento de su objetivo, las acciones del Gobierno orientadas a ejecutar el plan de igualdad de oportunidades deberán: a) promover y garantizarles a las mujeres el ejercicio pleno de sus derechos políticos, civiles, económicos, sociales y culturales y el desarrollo de su personalidad, aptitudes y capacidades que les permitan participar activamente en todos los campos de la vida nacional y el progreso de la nación; b) eliminar los obstáculos que les impiden a las mujeres el pleno ejercicio de sus derechos ciudadanos y el acceso a los bienes que sustentan el desarrollo democrático y pluricultural de la nación; c) incorporar las políticas y acciones de equidad de género e igualdad de oportunidades de las mujeres en todas las instancias y acciones del Estado, a nivel nacional y territorial.

\section{Ley 1009 de 2006}

Esta ley crea con carácter permanente el Observatorio de Asuntos de Género, organismo que tiene por objeto identificar y seleccionar un sistema de indicadores de género, categorías de análisis y mecanismos de seguimiento para hacer reflexiones críticas sobre las políticas, los planes, los programas, las normas y la jurisprudencia para el mejoramiento de la situación de las mujeres y de la equidad de género en Colombia. Su principal tarea es actuar como órgano permanente de recolección y sistematización de información cuantitativa y cualitativa de las diferentes fuentes nacionales e internacionales sobre la situación de las mujeres en Colombia y la equidad de género, teniendo en cuenta aspectos estadísticos, normativos, jurisprudenciales y administrativos (políticas, planes, proyectos y programas).

\section{Decreto 4463 de 2011}

Este decreto reglamenta la Ley 1257 de 2008 en cuanto a lo laboral, teniendo por objeto definir las acciones necesarias para promover el reconocimiento social y económico del trabajo de las mujeres, implementar mecanismos para hacer efectivo el derecho a la igualdad salarial y desarrollar campañas de erradicación de todo acto de discriminación y violencia contra las mujeres en el ámbito laboral. 
Con este decreto, el Gobierno nacional ordenó el diseño del Programa de Equidad Laboral con Enfoque Diferencial y de Género para las Mujeres por parte del Ministerio del Trabajo, el cual se concretó con la entrada en vigencia del CONPES 161 2013, contando con un marco normativo claro y con recursos para implementar las acciones diseñadas desde el Gobierno central.

Por otra parte, elimina la discriminación salarial y laboral contra las mujeres, promueve una cultura de igualdad de condiciones y la participación de la mujer en comisiones tripartitas de gobierno, empleadores y trabajadores, estableciendo así el Sello de Compromiso Social con las Mujeres como un estímulo a los empleadores del cumplimiento de estas disposiciones.

Pese a que tiene vigencia desde 2011, este sello de compromiso social solo se está poniendo en práctica desde 2016 con el programa EQUIPARES, que se encuentra en una etapa incipiente, poniendo de manifiesto el hecho de que el Gobierno nacional emitió leyes y decretos sin el respectivo soporte técnico para concretarlas, razón por la cual, cuatro años después, se inició una acción cuya ejecución debió ser inmediata.

\section{Ley 1450 de 2011}

Esta ley estableció el Plan Nacional de Desarrollo, denominado "Prosperidad para todos", el cual contemplaba garantizar el funcionamiento del Sistema de Protección Social, que recoge, en términos generales, tres grandes componentes: la seguridad social integral -salud, riesgos profesionales y protección al cesante-, la promoción social y las políticas y programas de formación del capital humano. Uno de sus grandes objetivos es garantizar la igualdad de oportunidades a toda la población. Esto implica, entre otros, normas y políticas públicas para consolidar sistemas de salud y educación con cobertura universal, sostenibles y de calidad.

Entre los lineamientos estratégicos para generar un entorno de igualdad de oportunidades para la prosperidad social se encuentran: acceso y calidad en salud universal y sostenible, revisar, actualizar y unificar gradualmente los planes de beneficios y regular los servicios excluidos del plan de beneficios mediante una instancia de evaluación de tecnología, entre otros.

El PND establece en su artículo 177 la necesidad que desde el Gobierno central se adopte una política de equidad de género. Sobre el particular, el artículo establece: 


\begin{abstract}
Artículo 177. Equidad de género. El Gobierno Nacional adoptará una política pública nacional de Equidad de Género para garantizar los derechos humanos integrales e interdependientes de las mujeres y la igualdad de género, teniendo en cuenta las particularidades que afectan a los grupos de población urbana y rural, afrocolombiana, indígena, campesina y Rom. La política desarrollará planes específicos que garanticen los derechos de las mujeres en situación de desplazamiento y el derecho de las mujeres a una vida libre de violencia.

Esta política pública será construida de manera participativa bajo la coordinación de la Alta Consejería para la Equidad de la Mujer (ACPEM), la cual será fortalecida institucional y presupuestalmente para el cumplimiento efectivo de sus responsabilidades y funciones.

Parágrafo. La política pública asegurará el cumplimiento del Estado colombiano de los estándares internacionales y nacionales en materia de Derechos Humanos de las Mujeres con un enfoque multisectorial y transversal.
\end{abstract}

Así las cosas, este artículo enmarca la posterior construcción de la política pública de género, sin embargo, en él se reconocen unas líneas de trabajo priorizadas, como son el tema de la violencia y las mujeres en situación de desplazamiento, desconociendo al empleo como posibilitador de la realización personal en muchos ámbitos.

\title{
Ley 1496 de 2011
}

Esta ley "garantiza la igualdad salarial y de retribución laboral entre mujeres y hombres, se establecen mecanismos para erradicar cualquier forma de discriminación y se dictan otras disposiciones". Esta norma establece que tanto hombres como mujeres tendrán garantizada la igualdad salarial y la retribución salarial, estableciendo mecanismos que permitirán que dicha igualdad sea real y efectiva tanto en el sector público como en el privado, y determinando los lineamientos generales que permiten erradicar cualquier forma discriminatoria en materia de retribución laboral.

En el marco de esta norma, el empleador deberá tener en cuenta los siguientes factores de valoración salarial: la naturaleza de la actividad a realizar, el acceso a los medios de formación profesional, las condiciones en la admisión en el empleo, las condiciones de trabajo, la igualdad de oportunidades y de trato en materia de empleo y ocupación, con objeto de eliminar cualquier discriminación y complementos salariales. Debe tenerse en cuenta que el incumplimiento por parte del empleador dará lugar a multas de cincuenta (50) a quinientos (500) salarios mínimos legales mensuales vigentes imputables a la empresa. El Ministerio del Trabajo, por medio de la autoridad que delegue, fijará la sanción 
a imponerse, la cual se hará efectiva a través del Servicio Nacional de Aprendizaje (SENA).

Para garantizar la igualdad salarial o de remuneración, las empresas -tanto del sector público como del privado- tendrán la obligación de llevar un registro de perfil y asignación de cargos por sexo, funciones y remuneración discriminando clase o tipo y forma contractual.

Así las cosas, esta norma comparte el espíritu de las convenciones de la OIT ya presentadas, pero dota al Estado de la posibilidad de asegurar el cumplimiento de los criterios de igualdad en términos de salarios, por lo tanto, de presentarse incumplimiento, se generarán multas de hasta ciento cincuenta (150) salarios mínimos legales mensuales vigentes. El Ministerio del Trabajo, por medio de la autoridad que delegue, fijará la sanción a imponerse, la cual se hará efectiva a través del SENA.

Lineamientos de la Política Pública de Equidad de Género para las Mujeres de 2012 Este documento fue elaborado por el Gobierno del presidente Juan Manuel Santos para definir el marco sobre el que se deben desarrollar los planes específicos que garanticen los derechos de las mujeres en situación de desplazamiento y el derecho de las mujeres a una vida libre de violencia, asegurando el cumplimiento por parte del Estado colombiano de los estándares internacionales y nacionales en materia de derechos humanos de las mujeres con un enfoque multisectorial y transversal.

Este lineamiento se encuentra soportado en once estrategias y cuatro ejes fundamentales: lineamientos en prevención de las violencias, lineamientos en atención integral y diferenciada, lineamientos en articulación y coordinación interinstitucional y lineamientos de seguimiento y monitoreo, sobre los que se organiza la visión que se mantiene en Colombia sobre lo que debe desarrollarse en una política pública con enfoque de género.

Esto resulta de suma importancia en el desarrollo de un enfoque de género para las políticas públicas en Colombia, teniendo en cuenta estrategias de intervención sectorial y multisectorial, de fortalecimiento institucional y de transformación cultural que permitan en conjunto la superación de las inequidades de género que afectan a las mujeres y les garanticen igualdad de oportunidades.

CONPES 161 de 2013

Este documento presenta la Política Pública Nacional de Equidad de Género y precisa el plan de acción indicativo para el período 2013-2016, el cual inclu- 
ye el Plan integral para garantizar una vida libre de violencias. Las problemáticas abordadas y priorizadas en este documento reflejan aspectos centrales de las desigualdades que afectan a las mujeres en nuestro país, evidenciando la pertinencia de su tratamiento intersectorial en forma articulada por parte del Estado.

Este CONPES propone, entre otras cosas, la transformación cultural y la construcción de paz a partir de la eliminación de las prácticas que construyen, reproducen y refuerzan la violencia y la intolerancia y vulneran derechos de las mujeres. Este eje se centra en tres vertientes. La primera, en fortalecer los espacios, mecanismos, sistemas y herramientas institucionales. La segunda, en el reconocimiento social de las violencias que afectaron a las mujeres en el marco del conflicto; y la tercera, en una estrategia de comunicaciones asertivas y pedagógicas que sirvan como herramientas de promoción e interiorización del tema de género en el accionar de la sociedad en general.

Plantea, además, la autonomía económica y el acceso a activos, fomentando y potenciando la autonomía económica de las mujeres -tanto a nivel de ingresos como de acceso y control a bienes y servicios- y la participación de las mujeres en escenarios de poder y toma de decisiones a partir de acciones, a través de las cuales se avance en el fortalecimiento de la participación social, cultural y política de las mujeres, de manera que sus aportes logren incidir activamente en la construcción de paz y desarrollo del país.

Incluye también directrices respecto a la salud y los derechos sexuales y reproductivos, estableciendo la necesidad de precisar acciones dirigidas a elaborar y poner en funcionamiento herramientas, programas y procesos para fortalecer el enfoque diferencial de derechos en las condiciones de acceso y la calidad de la atención en los diferentes niveles del sistema de salud y en el ejercicio efectivo de los derechos sexuales y reproductivos de las mujeres en todo su ciclo vital.

Por último, este documento le otorga gran importancia a los procesos educativos, para lo que pone en funcionamiento herramientas, programas y procesos para fortalecer el enfoque diferencial de derechos y adelantar acciones dirigidas a disminuir las barreras de permanencia de las mujeres por razones de género en el sistema educativo colombiano.

\section{Ley 1753 de 2015}

Por medio de esta Ley se expide el Plan Nacional de Desarrollo 2014-2018 "Todos por un nuevo país”. Su Artículo 129, de evaluación de la política pública nacional de equidad de género para las mujeres y de la política pública para la 
prevención de riesgos, la protección y garantía de los derechos de las mujeres víctimas del conflicto armado, establece:

\begin{abstract}
El Gobierno Nacional realizará una evaluación participativa de la Política Pública Nacional de Equidad de Género para las Mujeres y de la Política Pública para la Prevención de Riesgos, la Protección y Garantía de los Derechos de las Mujeres Víctimas del conflicto armado. El diseño de estas evaluaciones iniciará en el primer semestre de 2016 y a partir de sus hallazgos se ajustarán las acciones, metas y presupuestos de estas políticas para el presente cuatrienio donde se incluirán las acciones que permitan avanzar en la protección y garantía de los derechos de las mujeres rurales, afrocolombianas, negras, raizales, palanqueras e indígenas, que contribuyan a su estabilización social y económica, con un enfoque territorial, etario y de justicia.

El Departamento Nacional de Planeación y la Consejería para la Equidad de la Mujer propondrán a la Comisión Intersectorial para la Implementación de la Política Pública Nacional de Equidad de Género el mecanismo para la participación de las organizaciones de mujeres y de mujeres víctimas en la evaluación y seguimiento de las políticas a las que hace referencia el presente artículo.

La Consejería para la Equidad de la Mujer, con el apoyo de las entidades que hacen parte de la Comisión Intersectorial para la Implementación de la Política Pública Nacional de Equidad de Género, adoptará acciones concretas para la armonización de las políticas a las que hace referencia el presente artículo, con los planes de desarrollo territorial.

El Departamento Nacional de Planeación y el Ministerio de Hacienda y Crédito Público diseñarán un mecanismo que permita a las entidades del Gobierno Nacional incluir el enfoque diferencial de género en sus procesos de planeación y presupuesto.
\end{abstract}

Con esta determinación, el Gobierno nacional prioriza como línea de trabajo el enfoque de género y especialmente el empoderamiento femenino en temas laborales, en el que afianza el concepto de "equidad". Además, abre espacios de fortalecimiento para mujeres víctimas del conflicto armado, transversalizando el enfoque diferencial de género e incluyéndolo en la política pública más importante para el país en los últimos años, determinada por las acciones encaminadas a la reparación integral a víctimas, direccionándolas a los demás niveles territoriales, logrando así que el tema también se incluya en la agenda gubernamental departamental y local a lo largo y ancho del país.

Ley 1822 de 2017

Esta ley modifica los artículos 236 y 239 del Código Sustantivo del Trabajo, con- 
siderando la necesidad de iniciar la licencia de maternidad una semana antes del parto, tiempo que se disminuye, pues antes era de dos semanas. La licencia de maternidad en total es de dieciocho semanas, incluida la semana de licencia preparto, pero se puede incrementar si el bebé es prematuro o si es un parto múltiple.
El artículo 236 del Código Sustantivo establece: Licencia en la época del parto e incentivos para la adecuada atención y cuidado del recién nacido.
1. Toda trabajadora en estado de embarazo tiene derecho a una licencia de die- ciocho (18) semanas en la época de parto, remunerada con el salario que deven- gue al momento de iniciar su licencia.
2. Si se tratare de un salario que no sea fijo como en el caso del trabajo a destajo o por tarea, se tomará en cuenta el salario promedio devengado por la trabajado- ra en el último año de servicio, o en todo el tiempo si fuere menor.
3. Para los efectos de la licencia de que trata este artículo, la trabajadora debe presentar al empleador un certificado médico, en el cual debe constar:
a) El estado de embarazo de la trabajadora;
b) La indicación del día probable del parto, y
c) La indicación del día desde el cual debe empezar la licencia, teniendo en cuen- ta que, por lo menos, ha de iniciarse dos semanas antes del parto.
Los beneficios incluidos en este artículo, y el artículo 239 de la presente ley, no excluyen a los trabajadores del sector público. [...]

En materia laboral, la ampliación de la licencia de maternidad representa una de las grandes y más recientes conquistas de la lucha por la verdadera implementación de un enfoque diferencial, toda vez que entiende a la mujer trabajadora de una manera distinta, reconociendo la importancia del vínculo inicial que se construye en esos primeros días entre madre e hijo y destacando la función y papel fundamental que desarrollan las mujeres en la sociedad.

\section{Realidad y alcance del enfoque de género frente a las políticas de Estado}

El género femenino, a lo largo de la historia, ha estado expuesto a un sinnúmero de vulneraciones, situándose en reiteradas ocasiones en una posición de considerable desventaja frente al género masculino (Brunet, 2009; CEPAL, 1996; Luján, 2013). Esta realidad sigue vigente en toda Latinoamérica y Colombia no escapa a ella, encontrándonos con un panorama en el que la brecha en términos de igualdad entre hombres y mujeres permanece abierta, soportándose principalmente en las dificultades del género femenino en temas como acceso a la educación y, especialmente, al empleo. 
Por una parte, debe considerarse que, desde la perspectiva de Amartya Sen (2000), el desarrollo de las naciones se mide desde las posibilidades de desarrollo que tengan cada uno de los individuos dentro de la sociedad. Por esta razón, el desarrollo integral del ser humano debe ser una prioridad.

Sin embargo, en Latinoamérica, y especialmente en Colombia, las posibilidades de desarrollo resultan ser más escasas, especialmente para las mujeres cuya participación en el mercado nacional es considerablemente menor a la de los hombres, alcanzando apenas un 33\% (OIT, 2019).

De acuerdo con la OIT (Organización Internacional del Trabajo, Comisión Económica para América Latina y el Caribe, Organización de las Naciones Unidas para la Alimentación y la Agricultura, Programa de las Naciones Unidas para el Desarrollo y ONU Mujeres, 2013), el trabajo, además de proveer el sustento, también es un eje de la vida de las personas y debería ser fuente de autonomía y satisfacción para todos. Pese a ello, las mujeres enfrentan mayores dificultades para ingresar al mercado del trabajo y, cuando lo hacen, experimentan peores condiciones, que se traducen en diferentes formas de discriminación y segregación.

Lo anterior, sustentado en circunstancias como las que plantea Brunet (2009):

La distribución igualitaria da cuenta de la presencia de las mujeres en el mercado de trabajo en condiciones cualitativas muy específicas, esto es, mayoritariamente como trabajadores mal pagados por la falta de equidad entre los géneros para la relación trabajo-salario (no se cumple, entre varones y mujeres, que a igual trabajo se reciba igual salario); 2) como trabajadores de servicios "feminizados" y en ocasiones sexualizados: secretarias, trabajadoras domésticas, prostitutas, azafatas, etc.; 3) en trabajos derivados de la cualidad "maternal" concebida como innata por el biologicismo ideológico: enfermeras, asistentas sociales, maestras; 4) como blancos del acoso sexual (basado en la relación de dependencia respecto del acosado); 5) como trabajadoras a media jornada debido a la necesidad de cumplir con la crianza de los hijos, y como trabajadoras de doble jornada (doméstica no remunerada y pública remunerada); 6) como "esposas que trabajan" y "madres que trabajan"; 7) como esposas y madres en primera instancia que, en segunda, también "salen a trabajar"; 8) como las que ganan un ingreso extra. (p. 20)

Frente a la realidad del género femenino en el mundo, Colombia ha venido realizando avances en materia de generación de políticas públicas tendientes a reconocer y mitigar las diferencias, generando espacios que permitan concretar la equidad de género. Colombia no ha sido ajena a esta tendencia mundial, por lo que en la actualidad cuenta con una serie de medidas legislativas y administrativas que responden a este criterio e imperiosa necesidad. 


\subsection{Desarrollo del concepto de "enfoque de género"}

La idea general de un enfoque de género irrumpió en la escena mundial hace ya varias décadas, encontrándose con los primeros instrumentos que reivindican la igualdad entre hombres y mujeres basados en los movimientos sociales, tales como el de las Sufragistas en Estados Unidos o los movimientos feministas europeos de la primera mitad del siglo XX.

Los primeros elementos que dan muestra de esta transformación se encuentran en los convenios de la Organización Internacional del Trabajo, para luego presentarse en instrumentos internacionales como la IV Conferencia Mundial de la Mujer (Beijing, 1995), en la que se renovó el compromiso de la comunidad internacional para lograr la igualdad entre hombres y mujeres, y se invitó a los Gobiernos y a los demás agentes a "[...] integrar la perspectiva de género en todas las políticas y los programas para analizar sus consecuencias en mujeres y hombres respectivamente, antes de tomar decisiones".

El estudio del género como factor determinante en las relaciones sociales tiene un contenido político importante, toda vez que la reivindicación femenina se realiza basada en un concepto político de "democracia", régimen bajo el cual la igualdad entre los hombres representa una premisa que podría considerarse exclusivamente teórica, pues en la práctica no funciona así (Cazés, 2004). Para su estructuración, el enfoque de género se discute alrededor del reconocimiento de la diversidad que se presenta entre los dos géneros reconocidos desde la biología, admitiendo el hecho de la diversidad como una línea importante para la construcción de la humanidad diversa, por lo que acepta que la opresión de un género sobre el otro va en contravía de la construcción de humanidad, que encuentra en su diversidad la más importante de sus características.

Continuando con Cazés (2004), su idea de género planteó esta perspectiva como un paradigma ético inédito, como visión filosófica contemporánea, como óptica renovada para comprender el desarrollo de la historia y como acción política democratizadora. Por tanto, encuentra en la teoría de género un referente para el estudio de la humanidad, que le permite interpretar la totalidad de las cosas.

En términos generales, la perspectiva de género se constituye hoy como una herramienta que permite enfocar, analizar y comprender las características que definen a mujeres y hombres de manera específica, así como sus semejanzas y diferencias Cazés (2004).

La perspectiva de género explora cuestiones relacionadas con la organización patriarcal que tiene el mundo, la manera como se desarrolla la mujer en este espacio, cómo el Estado satisface las necesidades de las mujeres en este 
entorno hostil y la diferencia entre el desarrollo personal y social de mujeres y hombres. Pero sobre todo cuestiona la organización social estructurada por la inequidad, la injusticia y la jerarquización, basadas en la diferencia sexual transformada en desigualdad genérica Cazés (2004). La perspectiva de género materializa y enriquece teóricamente el movimiento feminista en la medida en que este se reconozca como la lucha por la equidad de género y la reivindicación de la mujer en la sociedad, en la que se reconoce su diferencia y, desde allí, se toman medidas para ejercer sus derechos.

Frente al proceso que viene viviendo el mundo, en el que la tendencia hacia la generación de instrumentos que protejan a la mujer se concreta en cada vez más países -por lo menos en el hemisferio occidental-, la organización multilateral más importante también asumió una posición de protección y de asesoría técnica frente a los desafíos que la aplicación de este enfoque determina para los gobiernos. En este sentido, en julio de 2010, la Asamblea General de las Naciones Unidas creó ONU Mujeres, una entidad para la igualdad de género y el empoderamiento de la mujer. Así, dio un paso hacia el reconocimiento de este tema como prioritario en la agenda mundial.

La incorporación de una perspectiva de género integra la igualdad de género en las organizaciones públicas y privadas de un país, en políticas centrales o locales y en programas de servicios y sectoriales. Por tanto, esta nueva línea de trabajo de la ONU propone convertir el tema de género en una prioridad no solamente a nivel gobierno, sino también introduciendo un cambio social estructural en el que las escuelas, universidades, empresas y en general todos los espacios de desarrollo de una sociedad trabajen por la consolidación de medidas que erradiquen las prácticas discriminatorias y se comprometan con el desarrollo integral de sus individuos, especialmente de las mujeres.

\subsection{Equidad laboral de género}

"La equidad de género permite brindar a las mujeres y a los hombres las mismas oportunidades, condiciones y formas de trato, sin dejar de lado las particularidades de cada uno de ellos". Para alcanzar la equidad, resulta necesario incorporar medidas que compensen las desventajas que históricamente han arrastrado las mujeres, tal como lo explica la definición de la UNESCO (1998) en la Conferencia Intergubernamental sobre Políticas Culturales para el Desarrollo.

En cualquier organización, ámbito o esfera, la igualdad de oportunidades resulta parte integral de la inclusión laboral, que, a su vez, es indispensable 
para lograr un sentido de pertenencia y alineación con los valores de cualquier empresa.

La imperiosa necesidad de salvaguardar la igualdad de las mujeres y los hombres en Colombia ha tomado cada vez más fuerza, poniendo en evidencia la necesidad de construir un diálogo de equidad de género común, abierto, consecuente y frecuente. Asimismo, se ha procurado la implementación de políticas laborales con enfoque de género en las diferentes fases de la relación laboral a través de los procesos de selección para ocupar cargos vacantes desde su reclutamiento y contratación de personal, la ejecución de la relación laboral e incluso hasta la terminación de los contratos de trabajo, procurando y promoviendo la implementación de mejores prácticas desde el punto de vista del capital humano. Esto, con la finalidad única de aprovechar la diversidad como una ventaja competitiva y no como una desventaja desde el punto de vista laboral o empresarial, mejorando así el clima laboral, la productividad e incluso la imagen de los representantes del mercado laboral.

\subsection{Igualdad de género laboral}

Desde hace muchos años, la OIT se ha propuesto promover la igualdad de oportunidades para que las mujeres y los hombres accedan a un trabajo decente, a través de la expedición de los Convenios 100, 111, 156 y 183 y la Declaración de la OIT relativa a los principios y derechos fundamentales en el trabajo.

Para la OIT, la igualdad de oportunidades reúne una serie de elementos que la caracterizan consistentes en "un trabajo bien remunerado, productivo y realizado en condiciones de libertad, equidad, seguridad y dignidad humana”. Asimismo, estima que

la igualdad de género constituye un elemento decisivo de las actividades encaminadas a la consecución de sus cuatro objetivos estratégicos: (i) Promover y cumplir las normas y los principios y derechos fundamentales en el trabajo, (ii) Generar mayores oportunidades para que las mujeres y los hombres puedan tener un empleo e ingresos dignos, (iii) Mejorar la cobertura y la eficacia de una seguridad social para todos, y (iv) Fortalecer el tripartismo y el diálogo social.

El Programa de Trabajo Decente propuesto por la OIT es de carácter transversal, cuya ejecución resulta efectiva mediante la aplicación de una política e intervenciones institucionales integradas y coordinadas.

Lo anterior implica la presencia de lo que la OIT ha denominado "objetivos 
estratégicos", los cuales comprenden: la promoción de los derechos fundamentales, la creación de empleo, la protección social y el diálogo social. Así las cosas, la aplicación del enfoque de igualdad de género y de trabajo decente es parte del proceso propuesto por esta institución, cuyo objetivo principal es

\begin{abstract}
lograr una mayor igualdad en las oportunidades de empleo mediante la adopción de medidas, que también apuntan a mejorar el acceso de la mujer a la educación, la formación profesional y la atención de salud, a la vez que se toma debidamente en cuenta el rol femenino de la economía de la prestación de cuidados, por ejemplo, mediante medidas para armonizar la vida laboral y familiar e incentivos en el ámbito laboral para la prestación de servicios de guardería y las licencias parentales.
\end{abstract}

\title{
4.4. Enfoque de género en Colombia
}

El Ministerio del Trabajo, en ejercicio de lo ordenado por la Ley 1257 de 2008 y el Decreto Reglamentario del Sector Trabajo 4463 de 2011, tiene entre sus obligaciones la promoción de los derechos humanos de las mujeres en el mundo del trabajo. En este punto, resulta importante destacar que la misma entidad manifiesta la

existencia de profundas brechas entre hombres y mujeres que generan una extendida discriminación por razones de sexo, brecha salarial y ocupacional, y que desconoce los derechos humanos de las mujeres. La presencia de factores culturales ligados a la estructura patriarcal, limita el ejercicio de estos derechos.

Es así como resulta que el enfoque de género, en su más amplia definición, está orientado a observar, estudiar y transformar las diferencias culturales, económicas y políticas en la construcción de la condición y posición de hombres y mujeres, que generan desigualdades y se expresan en situaciones de discriminación y exclusión social. La incorporación progresiva de este concepto en el ámbito empresarial y laboral resulta indispensable cuando observamos la necesidad de apreciar y valorar la realidad desde una perspectiva de justicia e igualdad. (UNPA, PNUD, UNICEF y ONU Mujeres, 2012).

De esta forma, lo que se pretende principalmente es la promoción de la igualdad de oportunidades, con especial énfasis en el fortalecimiento de las capacidades y competencias de las mujeres a través de su empoderamiento como titulares de derechos (UNPA, PNUD, UNICEF y ONU Mujeres, 2012).

Colombia ha tenido un desarrollo progresivo alrededor del concepto de "en- 
foque de género", tanto académicamente como desde la perspectiva política, y se han adelantado esfuerzos por concretar medidas, programas y proyectos que permitan el empoderamiento femenino.

Todas las políticas implementadas por los diferentes Gobiernos colombianos se convirtieron el marco para la estructuración de planes, programas y proyectos en todo el territorio nacional, sobre todo en los últimos diez años, en el que el enfoque de género se convirtió en una de las líneas de tareas más importantes en el trabajo social en Colombia, no solamente desde la institucionalidad gubernamental, sino también desde la sociedad civil y la comunidad internacional.

La totalidad de los documentos de política pública formulados en Colombia han respondido a las mismas problemáticas que en la actualidad aquejan a esta población, situación que da cuenta de su poca efectividad, lo que lleva a afirmar que los avances en materia de género en Colombia se han dado especialmente en la legislación. Sin embargo, eso no ha repercutido en una verdadera transformación de la realidad de las mujeres colombianas. Las dificultades para la generación de ingresos y empleo decente, la baja participación política, los altos niveles de violencias basadas en género, los problemas para el acceso a la salud sexual y reproductiva y a la educación, o las demoras injustificadas en la protección de sus derechos al interior de las instancias competentes son reconocidos por el Gobierno nacional. Incluso, las líneas de política y las acciones formuladas han sido similares, por lo que resulta necesario retomarlas en las diversas políticas que se están ejecutando en la actualidad.

El poco éxito de las políticas públicas de género en Colombia ha sido el resultado de la confluencia de diversos factores, entre ellos, la situación propia del país y el conflicto armado, pero pese a lo difícil del camino, Colombia hoy cuenta con una política pública de género que se soporta en la consideración de la mujer como la fuerza social más grande del país y no una minoría. Pero se enfrenta en la realidad al hecho de que, pese a ser mayoría, su participación en todos los aspectos de la vida social sigue siendo mínima, especialmente en temas laborales, en los que la discriminación sigue dejando una huella.

La Política Pública Nacional de Equidad de Género para las Mujeres, en sus lineamientos, incorpora como herramientas conceptuales el principio de igualdad y no discriminación, el análisis de género y el enfoque diferencial de derechos. En este desarrollo amplio del concepto de "equidad", adopta las nociones de "igualdad", "no discriminación" y "diversidad". 


\subsection{La brecha salarial en Colombia}

Uno de los principales escenarios dentro del contexto laboral que evidencia mayor desigualdad de género es que "las mujeres tienen salarios menores que los hombres pese al aumento en su participación laboral, al mayor número de horas trabajadas y a la equivalencia entre hombres y mujeres de ciertas características observables, tales como la educación" (Sabogal, 2012, p. 54).

En este sentido, cifras presentadas por el Departamento Administrativo Nacional de Estadística (DANE, 2019) determinaron que en Colombia la brecha salarial existente entre hombres y mujeres, según la media, es del 12,9\% para el año 2019, demostrando que por cada 100 pesos que recibe un hombre como contraprestación a su servicio personal, una mujer gana 87 pesos. Brecha que se agudiza aún más en el sector informal de la economía, en el que las mujeres devengan un $29 \%$ menos que los hombres en el ingreso laboral mensual y un 2,9\% menos en el ingreso por hora.

A través del Convenio 100, la OIT busca garantizar y promover el principio de igual remuneración para hombres y mujeres frente a un trabajo valorado en las mismas condiciones y características, ofreciendo algunas directrices a los Estados y estableciendo medidas enfocadas a los empleadores para que procuren disminuir la brecha existente. Con el transcurrir del tiempo ha alcanzado una baja, pero no la suficiente, estando lejos de su absoluta erradicación.

Los mecanismos propuestos por la OIT (2019) para garantizar una igualdad en la remuneración se materializan a través de evaluaciones del empleo, en las que se fijan tasas de remuneración salarial justas que no contemplan al género como un criterio determinante para fijar la contraprestación y pretendiendo establecer una media en el mercado laboral con el fin de garantizar la equidad. El artículo 2.1 de la Convención resulta ser el eje central, mediante el cual se establece que las mujeres tienen derecho a recibir el mismo salario que los hombres cuando realizan un trabajo del mismo valor.

En este orden de ideas, subsisten razonamientos erróneos como "las mujeres trabajan menos respecto a los hombres porque deben ser quienes se ocupan de las labores del hogar", o que determinadas labores son propias de un género u otro. Estos falsos ideales impiden en la práctica que hombres y mujeres desarrollen su proyecto de vida como desean. Se puntualiza que dichos estereotipos propician conductas que subvaloran el trabajo de la mujer y, de la misma forma, su remuneración.

El ordenamiento jurídico colombiano ha procurado enfocarse en garantizar la protección del derecho a la igualdad laboral y a la disminución de las brechas 
existentes entre hombres y mujeres. Sin embargo, la aplicación real y efectiva del derecho a la igualdad se ve en un sentido difuso, si se tiene en cuenta que muchas de las actividades llevadas a cabo "tradicionalmente" por hombres y mujeres en la sociedad son diferentes, así como sus retribuciones salariales:

[...] el problema es que los puestos que ocupan los hombres y las mujeres en el mercado de trabajo son muy diferentes y, por lo tanto, siguen existiendo diferencias, porque las categorías que mayoritariamente ocupan hombres tienen mayores salarios según la regulación de las cláusulas convencionales. (Rodríguez, 2008, p. 9)

La anterior circunstancia derivada de los estereotipos de género aún persistentes en la sociedad, que agudizan la brecha salarial existente en Colombia y en el mundo, son un claro indicativo de la necesidad de establecer políticas de inclusión de hombres y mujeres en todos los sectores de la economía y bajo las mismas condiciones laborales y salariales. En este sentido, la adopción de este tipo de medidas afirmativas serviría de instrumento jurídico para garantizar la ampliación sin limitaciones del género femenino al mercado laboral.

Con anterioridad a la adopción del Convenio 100 de la OIT, las Naciones Unidas, a través de la Declaración Universal de Derechos Humanos de 1948, estableció el principio de "Igual salario por trabajo igual". La adopción de dicho principio constituyó un avance fundamental en términos de igualdad en la retribución económica y salarial del género femenino, y dejó en evidencia la situación de desigualdad existente entre los salarios de hombres y mujeres.

El artículo 143 del Código Sustantivo del Trabajo en la legislación colombiana establece el principio de "Igual salario por trabajo igual", en el siguiente sentido:

\begin{abstract}
El primer numeral del artículo 143 establece los tres elementos que constituyen "igual trabajo": (i) igual cargo o posición, (ii) igual jornada (iii) e iguales condiciones de eficiencia en el desempeño de la labor. La concurrencia de estos tres elementos da lugar a la nivelación salarial entre trabajadores que desempeñan un mismo trabajo, pero no devengan una remuneración equivalente. (Díaz y Dimaté, 2016, p. 2)
\end{abstract}

De esta forma, en el año 2011 se expidió la Ley 1496, que trajo consigo un relevante cambio al Código Sustantivo del Trabajo, estableciendo que "Todo trato diferenciado en materia salarial o de remuneración, se presumirá injustificado hasta tanto el empleador demuestre factores objetivos de diferenciación". 1

1 Código Sustantivo del Trabajo, artículo 143 (1950). 
La Corte Constitucional, con base en el principio "a trabajo igual, salario igual" que establece "la obligación para el empleador de proporcionarles a sus trabajadores una remuneración acorde con las condiciones reales del trabajo. Es decir, una que provenga de la observación de elementos objetivos y no de consideraciones subjetivas, caprichosas o arbitrarias", ${ }^{2}$ ha decidido amparar el derecho a la igualdad mediante el mecanismo especialísimo de la acción de tutela, aunque este no resulta ser el medio idóneo para proteger el principio de "Igual salario por trabajo igual". Se ha considerado viable si se cumplen los requisitos existentes para su procedencia, específicamente que: (i) se trate de un asunto de importancia constitucional; y (ii) que sea evidente la existencia de elementos que deriven en desigualdad salarial potencialmente injustificada, concediendo así la protección de este derecho.

Respecto a la igualdad salarial en estricto sentido, se logran evidenciar en la actualidad diferencias salariales entre hombres y mujeres con funciones idénticas, que resultan de la aplicación de cláusulas contractuales en las que se establece una mayor remuneración para trabajadores que tenían más formación (que solían ser los trabajadores del sexo masculino). En este caso,
el tribunal estimó correcta esta diferencia salarial por esa distinción en la forma- ción, pero lo cierto es que no explicó la forma en que la diferencia en la forma- ción profesional podría justificar una distinción de retribución cuando realizan el mismo trabajo. (Rodríguez, 2008, p. 9)

Si bien resulta inadmisible la discriminación o diferenciación en razón a criterios subjetivos, tales como la raza, el sexo, el color, la orientación sexual, la opinión política o la religión, el idioma, el lugar de origen o el estatus social, entre otros, cuando se trata de diferenciación basada en factores como la "distinción en la formación", la "experiencia profesional" o "la titulación académica" también pone en evidencia una forma de inequidad y desprotección de género.

En Colombia, la Corte Suprema de Justicia ha señalado que para que pueda establecerse como no discriminatorio un trato diferencial en materia salarial y prestacional, resulta necesario demostrar que este trato es de carácter objetivo, por lo que no debe estar fundamentado en argumentos irrelevantes que constituyen criterios sospechosos. ${ }^{3}$

Al respecto, la Corte Suprema de Justicia estableció que:

2 Corte Constitucional de Colombia. (12 de julio de 2016). Sentencia T 369 de 2016, p. 2.

3 Corte Suprema de Justicia, Sala. Lab, SL16217-2014, p. 15, 2014. 
Si ambos trabajadores realizan el mismo trabajo; y si bien uno de ellos acredita los títulos académicos últimamente exigidos, esos títulos no se traducen en hacer más eficientemente el trabajo, o en realizar funciones adicionales con respecto a las desempeñadas por el otro trabajador. La respuesta al interrogante la encontramos en el artículo 143 CST: si dos trabajadores hacen el mismo trabajo, en condiciones de puesto, jornada y eficiencia iguales, deben recibir el mismo salario. Las condiciones adicionales, diferentes a las enunciadas, que exhiba uno de los trabajadores -se insiste: haciendo éstos el mismo trabajo-, no deberán repercutir en una mejor asignación salarial. ${ }^{4}$

En este orden de ideas, queda claro que no puede justificarse una diferenciación salarial entre dos trabajadores de género distinto que realizan las mismas funciones, aun cuando uno de estos tenga mayor experiencia y formación académica que el otro, debido a que se encuentran realizando las mismas actividades y tienen a su cargo las mismas responsabilidades. La diferencia estaría claramente plasmada si se le asignaran funciones adicionales o especializadas a uno de ellos, lo que daría a entender que sus trabajos no son iguales y sería admisible, en este caso, la asignación de un salario diferenciado para cada uno.

\subsection{Enfoque de género en las políticas públicas de empleo en Colombia}

La política de género aplicada en Colombia se ha construido basada en un diagnóstico de la situación de las mujeres y el poco avance logrado con los instrumentos previamente diseñados, por lo que se ha trazado como objetivo atacar los principales problemas que requieren atención para así garantizar el pleno goce de sus derechos, teniendo en cuenta las particularidades regionales, urbanas y rurales y las diversidades culturales propias de nuestro país, tales como las afrocolombianas, negras, palenqueras y raizal, indígenas, entre otros, además de otras subcategorías, como la ocupación de estas mujeres, entendiendo que las realidades de las campesinas, artesanas, pescadoras, trabajadoras agrícolas y profesionales, entre otras, son potencialmente diferentes entre sí, razón por la cual requieren ser reconocidas y analizadas en su particularidad.

Gracias a la concreción de la perspectiva de género como una unidad de análisis dentro del proceso de construcción de políticas públicas, el país puso su mirada sobre las mujeres y sus necesidades, y entendió el hecho de que, además de las labores históricas de cuidado a las que ha sido relegada, repre- 
sentan una fuerza laboral mayúscula contenida no solamente en el hecho de representar la mayoría de la población, sino también en el potencial que hasta ahora no se ha explotado.

De esta forma, en materia de empleo, la política pública de género en Colombia busca la plena participación de las mujeres en el mercado laboral con igualdad de oportunidades, superando los obstáculos que impiden su incorporación al mercado laboral, imprescindible para fortalecer su autonomía. Asimismo, se promueve el reconocimiento de la contribución de las mujeres al desarrollo del país, desde un análisis que privilegia su situación y posición específica en la sociedad.

Con miras a alcanzar la garantía constitucional al ejercicio del derecho a la igualdad y a la equidad de género, se orientan las relaciones laborales hacia la construcción de alternativas de trabajo decente y libre de discriminación laboral de cualquier índole. Esta situación se enmarca en el ejercicio pleno y efectivo de los derechos económicos y laborales de las mujeres desde un enfoque diferencial orientado a brindar igualdad de oportunidades, en el que la función principal del Estado es convertirse en el actor principal para el cumplimiento de estos derechos.

A través de diferentes mecanismos e instrumentos, se procura privilegiar la participación de la mujer en escenarios de poder y toma de decisiones, planteándose así el fortalecimiento de su participación social, cultural y política, de manera que sus aportes incidan activamente en la construcción de una sociedad más equitativa y justa. Por todo lo anterior, se plantean como iniciativas: (i) diseñar y ejecutar programas orientados a fortalecer la participación de las mujeres, teniendo en cuenta sus condiciones especiales en los distintos escenarios sociales, culturales y políticos; y (ii) hacer seguimiento y monitoreo a las normas establecidas para aumentar la participación de las mujeres en los escenarios de poder y toma de decisiones.

Desde lo laboral también se destaca la búsqueda de una conciliación de la vida familiar y laboral, situación que representa un reconocimiento a la labor fundamental que realiza la mujer en la sociedad como eje de la familia y responsable del cuidado de su hogar. Este trabajo se realiza bajo la consigna de que las labores de cuidado no son exclusivamente femeninas. Sin embargo, esta representa quizá la lucha más importante a la hora de materializar los conceptos de equidad e igualdad, toda vez que la cultura machista imperante dificulta las acciones en este sentido.

Reivindicando el derecho al trabajo como pilar fundamental para el ejer- 
cicio de otros derechos y como fórmula para la eliminación de las brechas de desigualdad entre hombres y mujeres, se reconoce la necesidad de redirigir acciones para que las empresas adopten esquemas más flexibles, los cuales faciliten a sus trabajadores - hombres y mujeres- cumplir con su trabajo y también con sus obligaciones familiares.

Pese a los avances logrados, resulta muy preocupante la situación actual del país originada por la pandemia del COVID-19. Debido a esto, muchos objetivos planteados en la política pública de género en materia de empleo no se están materializando, y se registra un desafortunado incremento de los índices de desempleo que ha afectado principalmente a las mujeres en nuestro país, sumado a la falta de recursos. Este hecho es aún más preocupante porque determina la perpetuidad de la situación de marginación de la mujer.

Finalmente, y pese a todo lo anterior, a la fecha no se evidencian acciones encaminadas a garantizar el desarrollo integral de la mujer trabajadora, toda vez que se limitan las acciones a trabajar por el problema del acceso a las oportunidades laborales sin ahondar en la necesidad de garantizar las condiciones que requiere una mujer para su desarrollo integral, teniendo en cuenta que estas condiciones, en la actualidad, están siendo más gravosas por los efectos sanitarios, contrastando así con las condiciones propias del enfoque de género.

\section{Recomendaciones para la generación de políticas públicas con enfoque de género}

El empleo no es solamente la materialización de un derecho fundamental reconocido en la Carta Política como derecho al trabajo y plasmado en el ordenamiento jurídico; por el contrario, esta situación trasciende la individualidad y garantiza la posibilidad de acceder a otros derechos, no solamente por parte del individuo que entrega su fuerza de trabajo, sino también para todo aquel que depende de él para garantizar su mínimo vital y una calidad de vida digna.

Frente a la situación de empleo de la mujer, el mercado de trabajo en América Latina continúa evidenciando fuertes desequilibrios que se manifiestan a través de las elevadas tasas de desempleo y de la baja calidad de las ofertas de empleo, situaciones estas que no garantizan una posición digna de la mujer en las relaciones laborales.

En este contexto, las mujeres enfrentan mayores dificultades para incorporarse al mercado laboral, experimentando diversas formas de discriminación y segmentación (Maurizio, 2010). Tanto en Colombia como en la mayoría de los países latinoamericanos, la brecha de género en materia de empleo sigue 
siendo muy amplia, condicionando negativamente a las mujeres en el acceso y la calidad del empleo.

A continuación se presenta una serie de recomendaciones para la implementación de una política pública en Colombia, encaminadas a promover el eventual desarrollo de iniciativas para la concreción del enfoque de género en materia laboral.

Frente a la construcción y aplicación de una política pública de empleo desde un enfoque de género comparada con la realidad en materia de acceso y oportunidades laborales para las mujeres, se hace indispensable tener en cuenta las siguientes consideraciones:

1. La política pública de género debe ser concretada en acciones tangibles, efectivas, y, sobre todo, consecuentes y permanentes. Por tanto, la implementación de programas y proyectos del orden nacional y local tendientes al empoderamiento femenino se hacen necesarios y urgentes, siempre y cuando estos garanticen una continuidad y no sean un proyecto del Gobierno de turno, que se queda sin ejecutarlo en su totalidad por la falta de gestión, de presupuesto y por el vencimiento del período gubernamental.

2. Para que exista una sociedad coherente, cohesionada e inclusiva se requiere generar políticas económicas que promuevan realmente el desarrollo social, principalmente en aquellas áreas que se consideran prioritarias, como es el caso de la salud, educación, rural y manufacturero, todas ellas en las que la mujer juega un papel fundamental.

3. Procurar la creación de políticas que hagan la vida realmente sostenible. Se requiere adoptar políticas que conlleven a la sostenibilidad de la vida a través de medidas de corresponsabilidad, que comprometan con actuaciones específicas inclusivas y responsables a todos los agentes que participan del bienestar de la comunidad en el marco de un modelo económico ajustado al desarrollo y cuidado de la vida de las personas, de su salud y de su entorno en un contexto de creciente escasez de recursos.

4. Promover una actividad económica que garantice de manera sostenible la satisfacción de las necesidades de todas las personas, en un escenario en el que la economía social juegue un papel fundamental a través de un comercio justo, que impulse las iniciativas locales y nacionales y que logre aportar al crecimiento del país, incentivando la participación de la mujer en el desarrollo de estas actividades.

5. Resulta indispensable incentivar la conformación de oficinas para asuntos de género en el orden departamental y municipal que sirvan como enlace efectivo y eficiente de protección y garantías para la equidad de género. 
6. Los trabajos relacionados con el cuidado de la familia y el hogar deben transformarse a una actividad especialísima que no distingue género, razón por la cual la consolidación de programas de concientización y formación en este sentido deben privilegiarse, abriendo un espacio para ello en la educación básica.

7. La política pública de empleo debe soportarse en elementos legales que permitan realmente poner en práctica la exigibilidad a las empresas de las medidas recomendadas en materia de género, como por ejemplo la obligatoriedad de la certificación de cumplimiento en la ejecución de dicha política en el ejercicio de su actividad.

8. La política pública de género no debe basarse en elementos de discriminación positiva, sino que, por el contrario, debe ajustarse a los conceptos de "igualdad" y "equidad", en los que se reconozcan las características que hacen especial a la mujer y sus diferencias, pero que se la trate como a un par en el ejercicio de la igualdad y equidad, capaz de desempeñarse con éxito en cualquier sector de la sociedad.

9. Se deben proteger los derechos de la mujer y el apoyo económico en todas las etapas de su vida, con el fin de permitirle alcanzar los grados de escolarización que le abran las puertas al campo laboral y al entorno social y económico del momento.

10. Se deberá velar por la protección de la salud de la mujer sin razones de discriminación por su capacidad de dar vida durante la mayor parte de su vida, ofreciendo un apoyo económico que le permita garantizar su cuidado.

11. Fomentar la actividad económica y de mano de obra mediante políticas económicas y de empleo que contribuyan a estabilizar la actividad económica, a través de políticas fiscales, medidas de protección social en la realidad actual (pandemia), transferencias y prestaciones especiales por condiciones de desempleo, inversión pública y reducciones fiscales para personas de bajos ingresos, incluyendo la pequeña y mediana empresa.

12. Establecimiento de políticas monetarias flexibles, otorgamiento de apoyo financiero y concesión de préstamos a las empresas, especialmente las pymes, en sectores específicos para fomentar la resiliencia y la recuperación frente a la crisis originada por el COVID-19, y crear empleo decente principalmente para las mujeres como parte del mercado laboral más afectado.

13. Apoyo al empleo y al mantenimiento de ingresos de las empresas y los trabajadores que se han visto afectados adversamente de forma indirecta, mediante medidas de protección social basadas en mecanismos existentes y/o la remuneración específica de trabajadores, en particular los trabajadores infor- 
males, ocasionales, temporeros y migrantes, así como los que desarrollan su labor por cuenta propia y a la mujer cabeza de hogar.

14. Crear disposiciones sobre conservación del empleo, en particular acuerdos sobre reducción de la jornada laboral o prestaciones parciales por desempleo para trabajadores por un período de tiempo determinado.

15. Generar políticas para el bien común en procura de aumentar las condiciones y oportunidades para la ciudadanía, y promover el desarrollo humano desde los principios de igualdad de oportunidades, sostenibilidad, participación, empoderamiento y garantía de derechos humanos, garantizando la protección de los bienes y recursos naturales, urbanos y digitales.

\section{Conclusiones}

Luego de realizar este recorrido por las diferentes definiciones, conceptos y propuestas de viabilidad de políticas de empleo desde un enfoque de género en Colombia, es posible afirmar que la tarea más grande que tiene el Estado colombiano en esta materia se encuentra en proporcionar las bases para un crecimiento con inclusión social. Este concepto implica el reconocimiento de la mujer como pilar fundamental en la fuerza laboral nacional, entendiéndola no solamente bajo un criterio de igualdad con el hombre, sino también como un sujeto de necesidades especiales, por lo tanto, su protección desde el Estado también debe darse de manera especial, a partir de políticas integradas que promuevan el trabajo decente y sus derechos mínimos.

Asimismo, resulta imprescindible la inversión por parte del Estado en la creación de empleos decentes ante esta nueva realidad que azota al país, y que resulta crucial para reducir la desigualdad y la precariedad laboral. En este sentido, el Estado colombiano, durante varios años, ha venido trabajando de manera continua y comprometida con la formulación y ejecución de una política pública que permita transformar la realidad de las mujeres en términos generales, dotándola de las herramientas necesarias para el efectivo goce de sus derechos en términos de igualdad de condiciones en todos los espacios de la vida social, política y económica del país, resultando indispensable formular políticas públicas en materia de empleo con enfoque diferencial de género, las cuales reivindiquen a la mujer trabajadora y se enfoquen en garantizar mejores condiciones de vida.

Bajo el concepto de "políticas públicas de empleo" se pueden agrupar todas las acciones e instrumentos diseñados desde el Gobierno central para atender 
una de las problemáticas más importantes que aqueja no solamente a Colombia, sino también a muchos países latinoamericanos: la falta de empleo. En Colombia. la política pública se encuentra diseminada en varios instrumentos y/o documentos que, en su conjunto, orientan esta actividad y dan directrices para la ejecución de planes, programas y proyectos para enfrentar esta problemática.

A través de este documento, se plantea una propuesta encaminada a fomentar y potenciar la autonomía económica de las mujeres, a nivel de ingresos y como fórmula para garantizar su participación en las actividades productivas y en el mercado laboral. A su vez, privilegia su inclusión en escenarios de poder y toma de decisiones, por lo que plantea el fortalecimiento de la participación social, cultural y política de las mujeres, de manera que sus aportes logren incidir activamente en la construcción de paz y desarrollo del país. Asimismo, destaca la búsqueda de una conciliación de la vida familiar y laboral, situación que representa un reconocimiento a la labor fundamental que realiza la mujer en la sociedad como eje de la familia y responsable del cuidado.

Para lograr concretar estos tres pilares fundamentales, se enfoca principalmente en las siguientes estrategias: (i) plena participación de las mujeres en el mercado laboral con igualdad de oportunidades; (ii) conciliación de la vida familiar y laboral; (iii) protección de los derechos de las mujeres en riesgo o víctimas de desplazamiento forzado y otras violencias contra las mujeres en el marco del conflicto armado; (iv) reconocimiento y fortalecimiento de las mujeres y sus diferentes formas organizativas en la construcción de la paz; (v) fomento a la participación de las mujeres en instancias de poder y toma de decisiones; (vi) garantías a las mujeres en todo su ciclo vital del enfoque diferencial en el sistema de salud y en los derechos sexuales y reproductivos; (vii) garantías a las mujeres en todo su ciclo vital del derecho a la educación con enfoque diferencial; (viii) promoción y fortalecimiento del acceso a la propiedad y a los recursos productivos; (ix) disminución de los factores de riesgo y/o vulnerabilidad de las mujeres frente al hábitat y al ambiente; (x) movilización y comunicación para la transformación cultural; y (xi) fortalecimiento institucional. 


\section{Bibliografía}

Acosta, P. (2007). La protección de los derechos de las mujeres en la Constitución colombiana. Revista Derecho del Estado, (20), 49-60. https://revistas.uexternado.edu.co/index.php/ derest/article/view/703.

Alonso, E. F. (2013). El derecho fundamental a la igualdad laboral. Jurisprudencia constitucional. Forum, (4), 37-58. https://core.ac.uk/download/pdf/77269089.pdf.

Alta Consejería Presidencial para la Equidad de la Mujer. (2012). Lineamientos de la Política Pública Nacional de Equidad de Género para las Mujeres. https://siteal.iiep.unesco.org/sites/ default/files/sit_accion_files/siteal_colombia_0446.pdf.

Asamblea General de las Naciones Unidas. (1979). Convención sobre la eliminación de todas las formas de discriminación contra la mujer. https://www.ohchr.org/sp/professionalinterest/pages/cedaw.aspx.

Asamblea General de las Naciones Unidas. (1996). Pacto Internacional de Derechos Económicos, Sociales y Culturales. https://www.refworld.org.es/docid/4c0f50bc2.html.

Bonardo, D. (2007). ¿Mujeres sin trabajo? Desafíos y cuestiones pendientes en las políticas públicas de formación y/o capacitación para el empleo en perspectiva de género. Revista Pilquen, 9(1), 1-8. http://www.scielo.org.ar/scielo.php?script=sci_arttext\&pid=S1851-31232007000100001.

Brunet, I. (2009). Pobreza y exclusión social desde la perspectiva de género. Revista Internacional de las Organizaciones, (3), 13-27. https://dialnet.unirioja.es/descarga/articulo/3342227.pdf.

Carreño, Y. (2018). El giro constitucional de la protección a las mujeres gestantes en Colombia. Entre la inserción laboral y la protección de los derechos. Femeris, 4(1), 58-79. https://e-revistas.uc3m.es/index.php/FEMERIS/article/view/4568.

Cazés, M. (2004). Perspectiva o enfoque de género, análisis de género y teoría de género. Paradigma ético, visión filosófica y de la historia, acción democratizadora. http://www.europrofem.org/contri/2_05_es/cazes/03_cazes.htm.

CEPAL. (1996). Violencia de género: un problema de derechos humanos. Unidad Mujer y Desarrollo. https://www.cepal.org/es/publicaciones/5855-violencia-genero-un-problema-derechos-humanos.

CEPAL. (2019). Protocolo Facultativo de la Convención sobre la eliminación de todas las formas de discriminación contra la mujer, adoptado por la Asamblea General de las Naciones Unidas en el año 1999. https://www.ohchr.org/sp/professionalinterest/pages/opcedaw.aspx.

Consejo Nacional de Política Económica y Social República de Colombia. (2013). Documento CONPES Social. Equidad de géneropara las mujeres. Departamento Nacional de Planeación. https://colaboracion.dnp.gov.co/CDT/Conpes/Social/161.pdf.

Cook, R. y Cusack, S. (2009). Estereótipos de género. Perspectivas Legales Transnacionales. University of Pennsylvania Press. https://www.law.utoronto.ca/utfl_file/count/documents/reprohealth/estereotipos-de-genero.pdf.

Corte Interamericana de Derechos Humanos. (1984). Opinión Consultiva OC-4/84 de 19 de enero de 1984. Propuesta de modificación a la Constitución Política de Costa Rica relacionada con la naturalización. https://www.corteidh.or.cr/docs/opiniones/seriea_04_esp.pdf.

Corte Interamericana de Derechos Humanos. (2009). Opinión Consultiva OC-18/03 de 17 de septiembre de 2003. Condición jurídica y derechos de los migrantes indocumentados. http://www. acnur.org/t3/fileadmin/Documentos/BDL/2003/2351.pdf?view=1. 
Departamento Administrativo de la Función Pública. (2014). Concepto 104251 de 2014. https:// www.funcionpublica.gov.co/eva/gestornormativo/norma.php?i=6360.

Departamento Nacional de Planeación. (2014). Plan Nacional de desarrollo "Todos por un nuevo pais” de Colombia (2014-2018). https://colaboracion.dnp.gov.co/CDT/PND/PND\%20 2014-2018\%20Tomo\%201\%20internet.pdf.

Díaz, J. y Dimaté, J. D. (2016). A trabajo igual, salario igual: la carga de la prueba en procesos de nivelación salarial según la jurisprudencia de la Corte Suprema de Justicia. Universidad de los Andes. https://una.uniandes.edu.co/index.php/ediciones/volumen-1/54-diaz-j-dimate-j-d.

Edo, M. (2002). Amartya Sen y el desarrollo como libertad. La viabilidad de una alternativa a las estrategias de promoción del desarrollo. https://repositorio.utdt.edu/handle/utdt/417.

El sector financiero emplea a más mujeres que hombres en Colombia. (2015). Revista Dinero. https://www.semana.com/economia/articulo/el-sector-financiero-emplea-mas-mujeres-hombres-colombia/215814/.

Espino, A., y Salvador, S. (2014). Un análisis de género de los costos laborales en Colombia. Ministerio del Trabajo de Colombia. Mimeo.

Esquivel, V. (Ed.). (2013). La economía feminista desde América Latina: Una hoja de ruta sobre los debates actuales en la región. ONU Mujeres. https://www.unwomen.org/-/media/headquarters/attachments/sections/library/publications/2012/la-economia-feminista-desde-america-latina-es.pdf?la $=$ es $\& v s=4841$.

Farah, I., Sánchez, C. y Wanderley, F. (2009). Politicas para la inserción laboral de mujeres y jóvenes en el Estado Plurinacional de Bolivia. CEPAL/ASDI. https://repositorio.cepal.org/bitstream/ handle/11362/3715/S2009225_es.pdf?sequence=1\&isAllowed $=y$.

Galvis, L. A. (2010). Diferenciales salariales por género y región en Colombia. Una aproximación con regresión por cuantiles. Revista de Economía del Rosario, 13(2), 235-277. https:// www.urosario.edu.co/urosario_files/f7/f74319db-9912-4878-a819-2eddf54663e2.pdf.

García Rojas, K., Ordoñez Herrera, J. S., García, S., Díaz, D. A. y Crespo Martín, D. (2020). Brecha salarial de género en Colombia. Departamento Administrativo Nacional de Estadística, Gobierno de Colombia. https://www.dane.gov.co/files/investigaciones/notas-estadisticas/ nov-2020-brecha-salarial-de-genero-colombia.pdf.

Hernández Sampieri, R., Fernández Collado, C. y Baptista Lucio, P. (2006). Metodología de la investigación. McGraw Hill. https://investigar1.files.wordpress.com/2010/05/1033525612mtis_sampieri_unidad_1-1.pdf.

Lahera, E. (2004). Politica y politicas públicas. División de Desarrollo Social, CEPAL. http:// repositorio.cepal.org/bitstream/handle/11362/6085/S047600_es.pdf.

Luján, M. (2013). Violencia contra las mujeres y alguien más... Departamento de Filosofía del Derecho, Moral y Política, Facultad de Derecho, Universidad de Valencia. http://roderic.uv.es/ bitstream/handle/10550/29006/Tesis\%20completa.pdf?sequence=1.

Marrugo-Salas, L. (2016). El acceso de la mujer a cargos de toma de decisiones en las empresas colombianas que cotizan en bolsa. Entramado, 12(1), 108-120. http://www.scielo.org.co/ pdf/entra/v12n1/v12n1a08.pdf.

Maurizio, R. (2010). Enfoque de género en las instituciones laborales y las políticas del mercado de trabajo en América Latina. CEPAL. https://www.cepal.org/es/publicaciones/5333-enfoque-genero-instituciones-laborales-politicas-mercado-trabajo-america-latina. 
Moine, M. B. (2013). Factores que inciden en el acceso de las mujeres a cargos de responsabilidad en la estructura organizacional. Ciencias Económicas, 1(10), 21-45. https://dialnet. unirioja.es/servlet/articulo? codigo $=5522966$.

Morán G. Alvarado, D. (2010). Métodos de investigación. Pearson Educación. https://mitrabajodegrado.files.wordpress.com/2014/11/moran-y-alvarado-metodos-de-investigacion-1ra.pdf

Naciones Unidas. (1966). Pacto Internacional de Derechos Económicos, Sociales y Culturales. http:// www.ohchr.org/SP/ProfessionalInterest/Pages/CESCR.aspx.

Observatorio del Servicio Público de Empleo. (2020). Mujeres en el Mercado Laboral Colombiano. http://filco.mintrabajo.gov.co/FILCO/faces/inicio.jsf.

Organización de las Naciones Unidas para la Agricultura y la Alimentación (FAO). (s.f.). Vocabulario referido a género. http://www.fao.org/docrep/x0220s/x0220s01.htm.

Organización de los Estados Americanos. (1994). Convención Interamericana para Prevenir, Sancionar y Erradicar la Violencia contra la Mujer "Convencion De Belem Do Para". https://www.oas. org/juridico/spanish/tratados/a-61.html.

Organización Internacional del Trabajo. (1951). C100 - Convenio sobre igualdad de remuneración, 1951 (núm. 100). https://www.ilo.org/dyn/normlex/es/f?p=NORMLEXPUB:12100:0::NO::P12100_ILO_CODE:C100.

Organización Internacional del Trabajo. (2009a). Empoderamiento de las mujeres: 90 años de la OIT en acción! https://www.ilo.org/gender/Events/Campaign2008-2009/WCMS_104931/ lang-es/index.htm.

Organización Internacional del Trabajo. (2009b). Mujeres en el trabajo, pasado y presente: como la noche y el dia. https://www.ilo.org/global/publications/world-of-work-magazine/articles/ ilo-in-history/WCMS_110118/lang--es/index.htm.

Organización Internacional del Trabajo. (2014). Igualdad de género y no discriminación en la gestión del empleo. Guía para la Acción. https://www.ilo.org/wcmsp5/groups/public/-mamericas/-.. ro-lima/-msro-san_jose/documents/publication/wcms_326274.pdf.

Organización Internacional del Trabajo. (2019). La brecha salarial entre hombres y mujeres en América Latina: En el camino hacia la igualdad salarial. https://www.ilo.org/wcmsp5/groups/public/mamericas/_-ro-lima/documents/publication/wcms_697670.pdf.

Organización Internacional del Trabajo y Programa de las Naciones Unidas para el Desarro1lo. (2009). Trabajo y Familia: Hacia nuevas formas de conciliación con corresponsabilidad social. https://www.ilo.org/wcmsp5/groups/public/-.-dgreports/-.-gender/documents/publication/wcms_111376.pdf.

Organización Internacional del Trabajo, Comisión Económica para América Latina y el Caribe, Organización de las Naciones Unidas para la Alimentación y la Agricultura, Programa de las Naciones Unidas para el Desarrollo y ONU Mujeres. (2013). Trabajo decente e igualdad de género. Políticas para mejorar el acceso y la calidad del empleo de las mujeres en América Latina y el Caribe. https://www.ilo.org/wcmsp5/groups/public/-mamericas/--ro-lima/--sro-santiago/documents/publication/wcms_233161.pdf.

Osborne, R. (2005). Desigualdad y relaciones de género en las organizaciones: Diferencias numéricas, acción positiva y paridad. Política y Sociedad, 42(2), 163-180. https://revistas.ucm. es/index.php/POSO/article/view/POSO0505230163A.

Programa de las Naciones Unidas para el Desarrollo en Colombia. (2014). Empoderamiento de la mujer. 
Enfoque. https://www.google.com.co/url?sa $=t \& r c t=j \& q=\&$ esrc $=s \&$ source $=$ web $\& c d=\& v e d=2 a-$ hUKEwjX2oLGnbbwAhXWHjQIHceAD6cQFjAAegQIAxAD\&url=http\%3A\%2F\%2Fwww. undp.org\%2Fcontent\%2Fdam\%2Fcolombia\%2Fdocs\%2FODM\%2Fundp-co-odmcolombia2014-2014.pdf\&usg=AOvVaw38wzvDXz-rzrmC42XTyiVz.

Programa de las Naciones Unidas para el Desarrollo en Colombia. (2017). Sello de Equidad Laboral EQUIPARES. https://www.co.undp.org/content/colombia/es/home/projects/sello-de-equidad-laboral-equipares.html.

Rodríguez, E. (2008). La regulación de la igualdad entre hombres y mujeres en la normativa laboral de los países nórdicos. Aequalitas: Revista jurídica de igualdad de oportunidades entre mujeres y hombres, (23), 6-15. https://dialnet.unirioja.es/servlet/articulo?codigo=2871997.

Ruiz, D. y Cádenas, C. (2005). ¿Qué es una política pública? IUS Revista Jurídica, (18).

Sabogal, A. (2012). Brecha salarial entre hombres y mujeres y ciclo económico en Colombia. Coyuntura Económica: Investigación Económica y Social, XLII(1), 53-91. https://www.repository.fedesarrollo.org.co/handle/11445/272.

Sen, A. (2000). El desarrollo como libertad. Gaceta Ecológica, (55), 14-20. https://www.redalyc. org/pdf/539/53905501.pdf.

UNESCO. (1998). Conferencia Intergubernamental sobre Políticas Culturales para el Desarrollo. Informe final. http://www.lacult.unesco.org/docc/1998_Conf_Intergub_sobre_pol_cult_para_des.pdf.

Unidad Administrativa Especial del Servicio Público de Empleo. (2016). Informe sobre brechas de género en el mercado laboral. https://info.undp.org/docs/pdc/Documents/COL/Informe\%20UAESPE_Ene-mar2016.pdf.

Valcárcel A. (1997). La política de las mujeres. Política y Sociedad, (32). https://www.researchgate.net/publication/27585544_La_Politica_de_las_Mujeres_de_A_Valcarcel.

\section{Legislación citada}

Organización Internacional del Trabajo. C111 - Convenio sobre la discriminación (empleo y ocupación), 1958 (núm. 111). Convenio relativo a la discriminación en materia de empleo y ocupación (Entrada en vigor: 15 junio 1960). Adopción: Ginebra, 42a reunión CIT (25 junio 1958) - Estatus: Instrumento actualizado (Convenios Fundamentales). El Convenio puede ser denunciado: 15 junio 2020 - 15 junio 2021. Constitución Política de Colombia. Código Sustantivo del Trabajo.

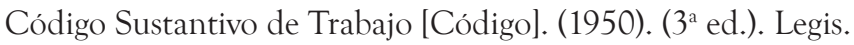

Congreso de Colombia, Código Sustantivo del Trabajo por el Decreto Ley 2663 del 5 de agosto de 1950 "Sobre Código Sustantivo del Trabajo", publicado en el Diario Oficial No 27.407 del 9 de septiembre de 1950, en virtud del Estado de Sitio promulgado por el Decreto Extraordinario No 3518 de 1949.

Congreso de Colombia, Ley 51 de 1981. (Junio 2). Reglamentada por el Decreto Nacional 1398 de 1990. "Por medio de la cual se aprueba la 'Convención sobre la eliminación de todas las formas de discriminación contra la mujer', adoptada por la Asamblea General de las Naciones Unidas el 18 de diciembre de 1979 y firmada en Copenhague el 17 de julio de 1980".

Congreso de Colombia, Ley 1009 de 2006. (Enero 23). Diario Oficial No. 46.160, de 23 de enero de 2006.

Congreso de Colombia, Ley 1450 de 2011. (Junio 16). Reglamentada por el Decreto Nacional 
734 de 2012, Reglamentado Parcialmente por el Decreto Nacional 2693 de 2012. Por la cual se expide el Plan Nacional de Desarrollo, 2010-2014.

Congreso de Colombia, Ley 1496 de 2011. (Diciembre 29). Por medio de la cual se garantiza la igualdad salarial y de retribución laboral entre mujeres y hombres, se establecen mecanismos para erradicar cualquier forma de discriminación y se dictan otras disposiciones.

Congreso de Colombia, Ley 1753 de 2015. (Junio 9) Por la cual se expide el Plan Nacional de Desarrollo 20142018 "Todos por un nuevo país.

Congreso de Colombia, Ley 1822 de 2017. (Enero 4). Por medio de la cual se incentiva la adecuada atención y cuidado de la primera infancia, se modifican los artículos 236 y 239 del Código Sustantivo del Trabajo y se dictan otras disposiciones.

Congreso de Colombia, Ley 248 de 1995. (Diciembre 29). Por medio de la cual se aprueba la Convención Internacional para prevenir, sancionar y erradicar la violencia contra la mujer, suscrita en la ciudad de Belem Do Para, Brasil, el 9 de junio de 1994.

Congreso de Colombia, Ley 581 de 2000. (Mayo 31). Por la cual se reglamenta la adecuada y efectiva participación de la mujer en los niveles decisorios de las diferentes ramas y órganos del poder público, de conformidad con los artículos 13, 40 y 43 de la Constitución Nacional y se dictan otras disposiciones.

Congreso de Colombia, Ley 731 de 2002. (Enero 14). Diario Oficial No. 44.678, de 16 de enero de 2002. Por la cual se dictan normas para favorecer a las mujeres rurales.

Congreso de Colombia, Ley 823 de 2003. (Julio 7). Por la cual se dictan normas sobre igualdad de oportunidades para las mujeres.

Congreso de Colombia. (14 de julio de 2011). Ley por la cual se adoptan reglas de organización y funcionamiento de los partidos y movimientos políticos, de los procesos electorales y se dictan otras disposiciones. [Ley 1475 de 2011].

Congreso de Colombia. (31 de mayo de 2000). Ley por la cual se reglamenta la participación de la mujer en los niveles decisorios de las diferentes ramas y órganos del poder público. [Ley 581 de 2000].

Congreso de Colombia. (4 de enero de 2017). Ley por medio de la se incentiva la adecuada atención y cuidado de la primera infancia, se modifican los artículos 236 y 239 del código sustantivo del trabajo y se dictan otras disposiciones. [Ley 1822 de 2017].

Constitución política colombiana. (1991). Asamblea Nacional Constituyente, Bogotá, Colombia, 6 de julio de 1991.

Constitución política de Colombia [Const.]. (1991). Artículo 13 [Título II]. http://www.secretariasenado.gov.co/senado/basedoc/constitucion_politica_1991.html.

Constitución política de Colombia [Const.]. (1991). Artículo 43 [Título II]. http://www.secretariasenado.gov.co/senado/basedoc/constitucion_politica_1991.html.

Decreto 1182 de 1999. Diario Oficial No 43.626, de 29 de junio de 1999. Departamento Administrativo de la Presidencia de la República. Por el cual se modifica la estructura orgánica del Departamento Administrativo de la Presidencia de la República. Resumen de Notas de Vigencia.

Decreto 1930 de 2013. 6 de septiembre de 2013. Diario Oficial No. 48.910 de 11 de septiembre de 2013. Departamento Administrativo de la Presidencia de la República. Por el cual se adopta la Política Pública Nacional de Equidad de Género y se crea una Comisión Intersectorial para su implementación. Resumen de Notas de Vigencia. 
Decreto 4463 de 2011. 25 noviembre de 2011. Por medio del cual se reglamenta parcialmente la Ley 1257 de 2008.

\section{Jurisprudencia citada}

Corte Constitucional de Colombia. (12 de agosto de 1992). Sentencia T 494 de 1992 [MP Ciro Angarita Varón].

Corte Constitucional de Colombia. (12 de julio de 2016). Sentencia T 369 de 2016 [MP María Victoria Calle Correa].

Corte Constitucional de Colombia. (13 de febrero 2013). Sentencia SU 070 de 2013 [MP Alex Julio Estrada].

Corte Constitucional de Colombia. (15 de septiembre de 1994). Sentencia C 410 de 1994. [MP Carlos Gaviria Díaz].

Corte Constitucional de Colombia. (21 de octubre de 2003). Sentencia C 964 de 2003. [MP Álvaro Tafur Galvis].

Corte Constitucional de Colombia. (25 de junio de 1992). Sentencia T 432 de 1992 [MP Ciro Angarita Varón].

Corte Constitucional de Colombia. (26 de octubre de 2016). Sentencia C 586 de 2016. [MP Alberto Rojas Ríos].

Corte Constitucional de Colombia. (29 de marzo de 2000). Sentencia C 371 de 2000. [MP Carlos Gaviria Díaz].

Corte Constitucional de Colombia. (9 de septiembre 1998). Sentencia C 481 de 1998. [MP Alejandro Martínez Caballero].

Corte Suprema de Justicia, Sala Laboral. (08 de mayo de 2019). Sentencia SL1682-2019. [MP Rigoberto Echeverri].

Corte Suprema de Justicia, Sala Laboral. (26 de noviembre de 2014). Sentencia SL1682-2019. [MP Carlos García Monsalve]. 